ISSN: 0514-7336

DOI: http://dx.doi.org/10.14201/zephyrus2018814770

\title{
LAS TÉCNICAS DECORATIVAS DEL CAMPANIFORME MARÍTIMO EN EL CENTRO-NORTE PENINSULAR A PARTIR DE NUEVOS HALLAZGOS EN EL YACIMIENTO DE LOS HUSOS I (LAGUARDIA, ÁLAVA)
}

\section{The decorative techniques in 'Maritime Bell Beakers' in the North-Centre of the Iberian Peninsula, from new findings at the site of Los Husos I (Laguardia, Alava)}

\author{
Cristina Camarero Arribas y Erik Arévalo Muñoz
}

Dpto. de Geografía, Prehistoria y Arqueología. Facultad de Letras UPV-EHU. Cl Tomás y Valiente, s/n. 01006 Vitoria.Correo-e: cristina.camarero.a@ehu.eus; erik.arevalo@ehu.eus.ID ORCID:0000-0002-4274-5268; 00000003-3879-8268

Recepción: 21/06/2017; Revisión: 14/09/2017; Aceptación: 20/11/2017

\footnotetext{
Resumen: A partir del hallazgo de dos fragmentos de Campaniforme Marítimo en el abrigo rocoso de Los Husos I (Laguardia, Álava) y debido a lo extraordinario de este tipo de cerámica en la provincia, estudiamos 14 vasos de las tres variantes del estilo Internacional -MHV, ILV y CZM- repartidos en 11 yacimientos en el contexto más próximo a Los Husos I.

Desde esta premisa en el siguiente trabajo presentamos los resultados tanto de los análisis tecnotipológicos como de la tecnología de la decoración, así como un programa experimental para replicar esas decoraciones y determinar la herramienta usada para elaborarlas. Se han utilizado un peine de hueso y cuatro especies de conchas distintas.

Los resultados de la experimentación se han comparado con las cerámicas arqueológicas y se ha determinado que la herramienta usada en todos estos recipientes era un peine de alfarero o gradina, debido a la similitud de estas improntas con las realizadas con el peine experimental y a la incompatibilidad con las huellas dejadas por las conchas usadas. Este análisis nos ha permitido reconstruir los gestos que la alfarera llevó a cabo para realizar estas decoraciones.

Palabras clave: Calcolítico; puntillado; arqueología experimental; técnicas decorativas cerámicas; peine; concha.

Aвstract: After the discovery of two 'Maritime Bell Beaker' pottery fragments in Los Husos I rock shelter (Laguardia, Álava) and due to the extraordinary nature of this type of Bell Beaker pottery in this region, we studied 14 vessels of the three types of 'Maritime Bell Beaker' -MHV, ILV and CZM- distributed in 11 sites in the surrounding area of Los Husos I.

In this paper we present the results of the techno-typological and decoration technology analysis. We also carry out an experimental program to replicate these decorations and determine the tool used to make them. We used a bone comb and four different shell species.
} 
We compared the results of the experimentation with archaeological potteries. We determined that the tool used in all these containers was a potter's comb, due to the similarity of the imprints with those made with the experimental comb and the incompatibility with the prints of the shells. This analysis allowed us to reconstruct the gestures that the potter made to make these decorations.

Key words: Chalcolithic; comb-decorated ceramic; experimental archaeology; ceramic decorative technology; potters comb; shell.

\section{Introducción ${ }^{1}$}

El punto de partida de este trabajo fue la identificación de un fragmento cerámico como Campaniforme Marítimo durante la revisión de los materiales de la antigua excavación del abrigo de Los Husos I (Laguardia, Álava). La escasez de este tipo de cerámica en la zona suscitó un estudio en profundidad de los motivos decorativos, las técnicas y herramientas empleadas por las alfareras calcolíticas ${ }^{2}$.

El estilo Marítimo Internacional es el tipo decorativo campaniforme más homogéneo dentro de las producciones cerámicas propias de este package, pues su presencia resulta común a toda el área de dispersión del Campaniforme en Europa. Su decoración se caracteriza por localizarse exclusivamente en el exterior del recipiente y se realiza mediante la aplicación seriada -sobre la pasta húmeda- de

1 Este trabajo ha sido posible gracias a la financiación parcial del Grupo de Investigación en Prehistoria del Gobierno Vasco (IT622-13). Los autores están financiados por el Programa Predoctoral del Dpto. de Educación, Política Lingüística y Cultura del Gobierno Vasco (referencias: PRE_2013_1_948 y PRE_2014_1_337 respectivamente). Queremos agradecer su ayuda y disponibilidad a J. Agirre, del Museo BiBat; a J. Sesma, encargado del depósito de materiales del Gob. de Navarra; a J. A. Tirado, del Museo de La Rioja; a S. San José del Gordailua de Guipúzcoa; a E. Carmona, por facilitarnos el acceso a los materiales de la provincia de Burgos, y a E. Huerta, del Hontza Museoa, por su ayuda en la experimentación con conchas. Para concluir, queremos expresar nuestra más sincera gratitud por su inestimable apoyo y consejo a J. Fernández Eraso, a Á. Armendariz Gutiérrez y a J. A. Mujika Alustiza.

2 Ante la falta de evidencias sobre el género de las personas que modelaron las cerámicas estudiadas y dado que los estudios etnográficos muestran que la alfarería es una actividad realizada mayoritariamente por mujeres (Calvo y García Rosselló, 2014: 19) optamos por usar el femenino, como ya han hecho otros autores (Blanco, 2015: 40). una concha, peine o ruedecilla de púas de sección cuadrangular o circular conformando bandas. Para el caso peninsular, existen tres variantes de estilo en función de la orientación y disposición de las decoraciones: MHV -Maritime Herringbone Variety o variante clásica-, MLV -Maritime Linear Variety, con líneas puntilladas horizontales paralelas- y CZM -Corded-Zone Maritime, cordado/puntillado- (Harrison, 1977). En el caso de la última de ellas -la CZM- el carácter variante radica fundamentalmente en el empleo de la técnica cordada, no puntillada, para la realización de las líneas delimitadoras de los frisos o bandas. Resulta necesario reseñar que han sido documentadas variantes a nivel local, como la denominada ILM o ILV -Intermedial Lined Maritime o Intermedial Lined Variety, que presenta líneas impresas horizontales paralelas en los espacios lisos situados entre los frisos decorados-, para el caso de la Meseta (Garrido-Pena, 2000: 198), que ya fue propuesta anteriormente por Hurtado y Amores (1982: 204).

\subsection{Contexto arqueológico}

Se han estudiado 14 vasos pertenecientes a 11 yacimientos, partiendo desde el yacimiento de Los Husos I y localizados en un radio de unos $100 \mathrm{~km}$, siendo el más cercano La Atalayuela (La Rioja) y el más alejado Tres Montes (Navarra).

El abrigo rocoso de Los Husos I (Laguardia, Álava) se ubica en la Sierra de Cantabria, dentro de la comarca de la Rioja Alavesa (Fig. 1). Descubierto en 1964, fue excavado por Apellániz entre 1965 y 1970, publicando los datos en su tesis doctoral (1974). Aunque en principio diseñó una excavación de $42 \mathrm{~m}^{2}$, tras la revisión de los datos publicados y del propio yacimiento, constatamos que abandonó 


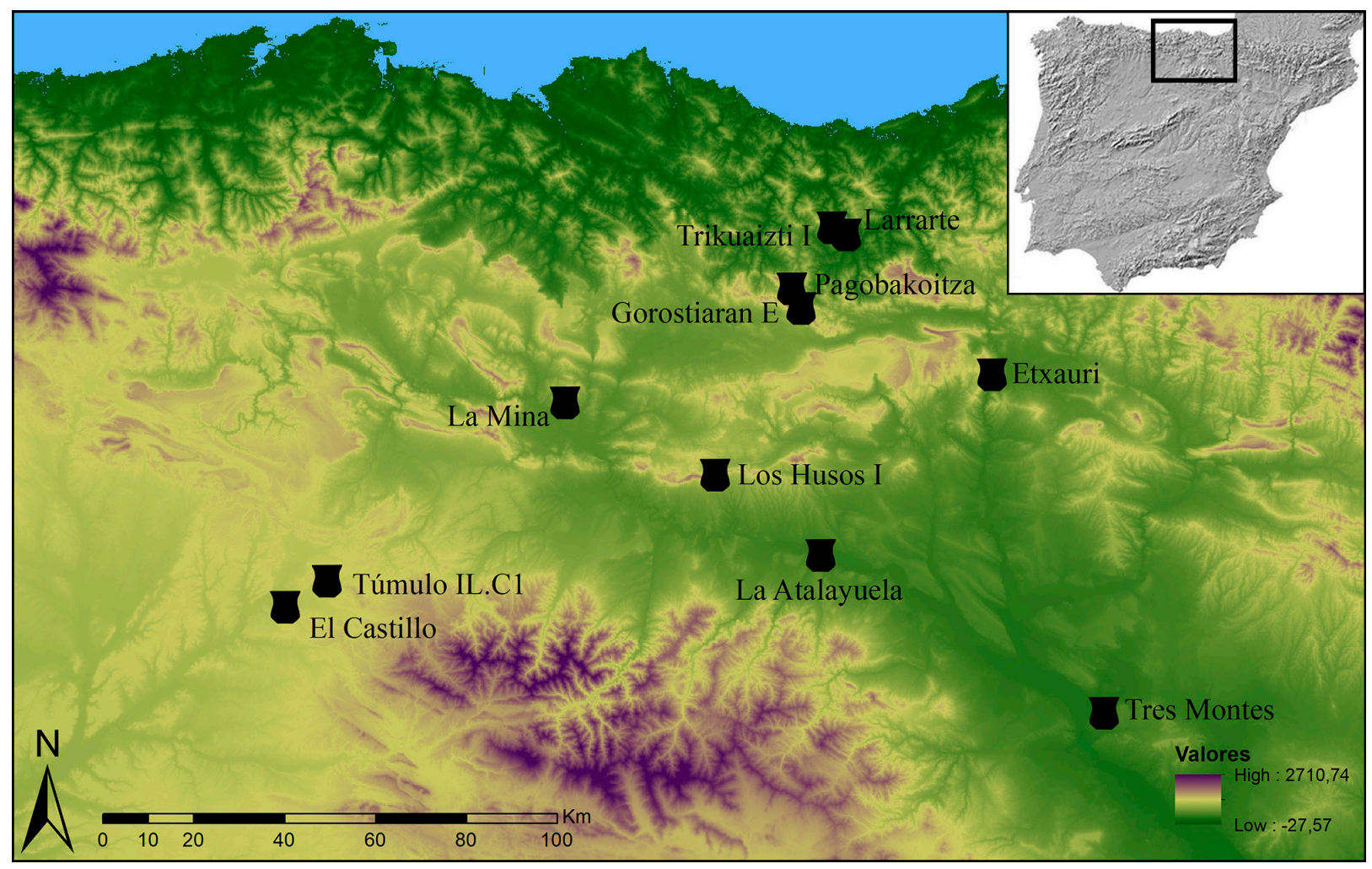

FIG. 1. Plano general de situación de los yacimientos estudiados.

las dos bandas interiores, limitándose a excavar una superficie de $30 \mathrm{~m}^{2}$ (Fig. 2). La serie estratigráfica identificada se compone de cuatro paquetes principales que, a su vez, subdivide en estratos -Paquete I: Estratos A, в у C; Paquete II: Estratos A, в у C; Paquete III, Estratos A y B; Paquete IV-, estableciendo una secuencia cronocultural que abarcaría desde el Neolítico Final hasta la época romana.

Fernández Eraso (2000, 2001, 2002a) emprendió una segunda excavación entre 1999 y 2001, con el propósito de obtener una secuencia estratigráfica completa y realizar nuevos análisis. En esta intervención, solamente se excavaron tres cuadros $-\mathrm{G} 2$, G4 y F4-, se identificaron 16 capas y se realizaron 18 dataciones de radiocarbono, estableciendo unas ocupaciones humanas desde el Neolítico Antiguo hasta la época romana. El abrigo se usó de forma continuada como establo, a excepción de un nivel funerario de cronología calcolítica (Fernández Eraso y Polo, 2008-2009; Polo y Fernández Eraso, 2010). En 2015 se realizó la última intervención, consistente en la recogida y cribado de las tierras procedentes del derrumbe del perfil $\mathrm{E}$, de la última excavación, provocado por una intervención no controlada de un clandestino (López-de-Ocáriz et al., 2016).

Los dos fragmentos de cerámica que se presentan a continuación pertenecen a cada una de esas excavaciones: el primero -LHI.C3.189.7- al Paquete IIA y el segundo -LHI.F4.9.280.186- a la Capa IX. Es complicado establecer una equivalencia estratigráfica entre las dos excavaciones, debido a la dispar interpretación que plantean ambos autores. A pesar de ello, creemos que la Capa Ix de Fernández Eraso es parte del denominado Paquete IIA de Apellániz; esta capa tiene una datación de $3710 \pm 40$ (Beta-148058), 2270-1972 cal AC ${ }^{3}$ (Fernández Eraso, 2002b: 46). Además, podríamos considerar la

3 Dataciones calibradas según OxCal v4.2.4 (Bronk Ramsey, 2013: r: 5); IntCal13 atmospheric curve (Reimer et al., 2013). 
datación correspondiente al Paquete IIC $3920 \pm 100$ вР (I-3.985), 2680-2132 cal AC (Apellániz, 1974: 126) un terminus ante quem para el nivel donde se localizó la pieza. En este sentido, las dataciones son garantes de la relación de ambas estratigrafías.

Aunque Los Husos i no lo es, la mayoría de las cerámicas campaniformes marítimas estudiadas provienen de yacimientos funerarios (Fig. 1) como el túmulo de Trikuaizti I (Beasain, Guipúzcoa), excavado entre 1981 y 1984 (Mujika y Armendariz, 1991), del que procede un vaso campaniforme de estilo CZM parcialmente reconstruido o el dolmen de Larrarte (Beasain, Guipúzcoa), muy cerca del anterior y excavado en 1986 (Mujika, 1986), donde se recuperaron 67 pequeños fragmentos de un mismo vaso campaniforme de estilo CzM. En la sierra de Aizkorri (Guipúzcoa) se encuentran el dolmen de Pagobakoitza y el túmulo de Gorostiaran Este, ambos descubiertos por Barandiarán en 1917 y excavados por Eguren, Aranzadi y Barandiarán en 1918. En el primero se recuperó un vaso campaniforme casi completo y un fragmento de un segundo recipiente, en Gorostiaran Este se hallaron 4 fragmentos de un mismo vaso, todos de estilo CZM (Aranzadi et al., 1919).

En Álava se sitúa el dolmen de La Mina (Molinilla), descubierto en 1927 y excavado en 1943 y 1951 (Marqués de Loriana, 1943, 1953; Barandiarán

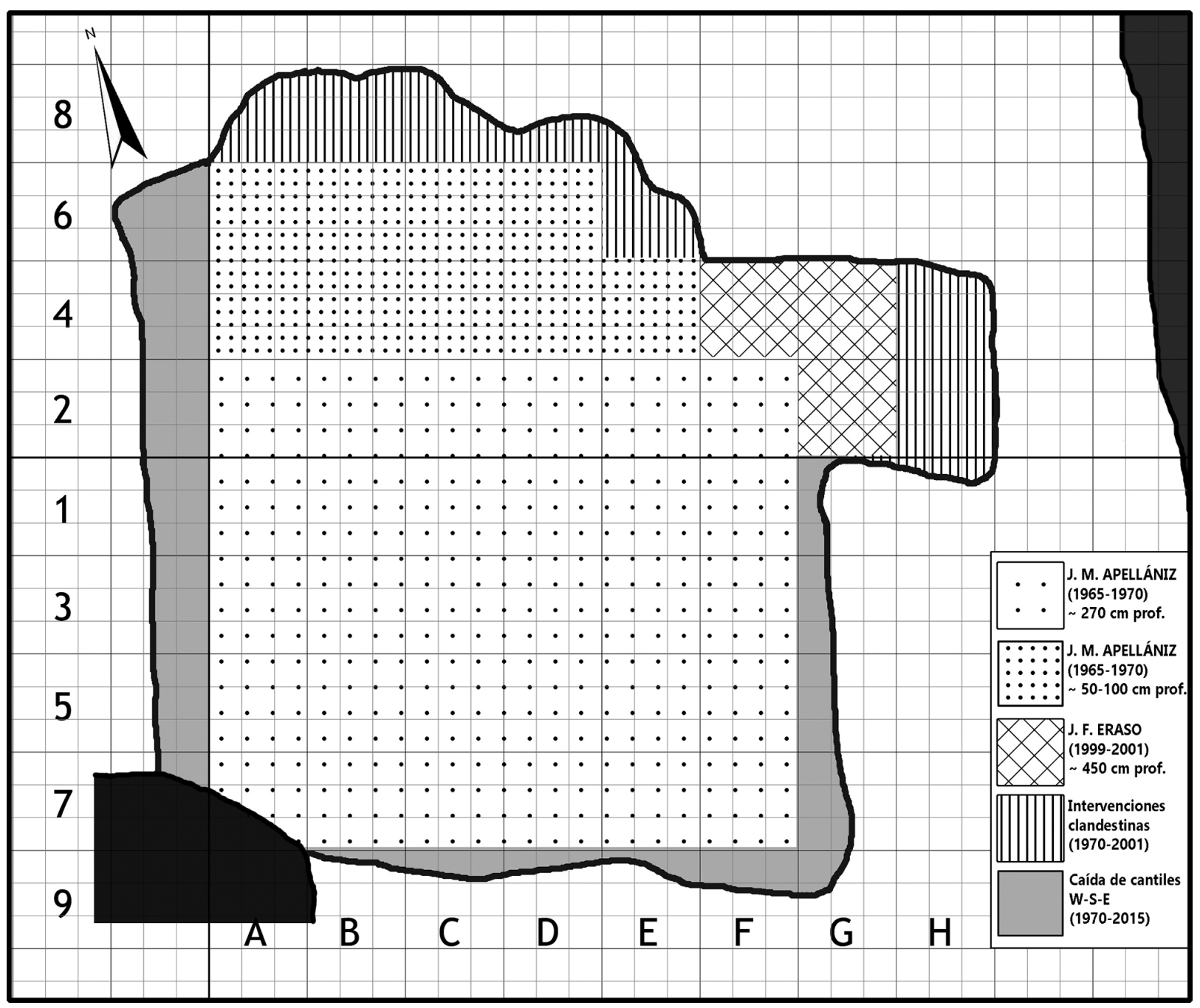

FIG. 2. Planta del yacimiento de Los Husos I (Laguardia) en su estado actual. 
y Fernández Medrano, 1971). La presencia de cerámica campaniforme $-\mathrm{MHV}$ - queda definida por varios fragmentos que fueron localizados en el corredor (Narvarte, 2005: 64; 2007).

La tumba calcolítica de La Atalayuela (Agoncillo, La Rioja) fue descubierta de modo casual tras la Guerra Civil y se excavó en 1970 (Barandiarán, 1978; Andrés y Barandiarán, 2004). Destacan de este yacimiento la cantidad y calidad de los materiales, que incluyen varios recipientes campaniformes de estilo Ciempozuelos y tres fragmentos de estilo CZM (Fig. 9, n. ${ }^{\circ}$ 1), de los cuales, actualmente en el Museo de La Rioja solo se conserva uno.

En la provincia de Burgos se localizan dos yacimientos, el Túmulo de IL.Ci/Páramo de Rebollo I (Cótar) y El Castillo (Burgos). El primero que se sitúa en una lengua de páramo que domina el curso del arroyo Cótar, fue excavado en los años 80 del s. xx (Uríbarri et al., 1987; Carmona, 2013b: 228) y se recuperaron tres fragmentos de un recipiente campaniforme estilo MHV. El Castillo se sitúa en un cerro de la margen derecha del río Arlanzón. Bajo las ruinas del castillo de cronología medieval y moderna se localizaron vestigios prehistóricos. En 1985, durante las obras de consolidación y recuperación de los restos arquitectónicos del castillo, se excavó el patio de armas (Uríbarri et al., 1987), proporcionando un lote de 39 fragmentos campaniformes -AOC, geométrico, MHV y CZM- sobre un total de 971 fragmentos cerámicos del Nivel XIII. En un principio, se consideró una ocupación tipo hábitat vinculada al Campaniforme (Uríbarri et al., 1987: 61), sin embargo, más tarde se ha propuesto que la ocupación calcolítica de este cerro es "algún tipo de manifestación funeraria, probablemente un dolmen o un túmulo, que fue destruida en momentos posteriores (¿Hierro I?)” (Carmona, 2013a: 62).

Los últimos dos yacimientos provienen de $\mathrm{Na}$ varra, el primero es Tres Montes (Bardenas Reales), que fue descubierto en 1991 y excavado en 1991 y en 1996 (Andrés et al., 1996, 2000, 2007). Se trata de una sepultura hipogea, peculiar dentro de la Península Ibérica, pero con notables semejanzas con algunos ejemplos franceses o germano-daneses. Un corredor megalítico da acceso a una cámara rectangular formada por losas que según los autores estaba rellena con tierra. En el lado suroeste de la cámara y adosados al exterior de las losas aparecen 7 agujeros de poste de un diámetro de $10 \mathrm{~cm}$. Debajo del suelo de losas, en el centro del recinto, apareció una inhumación en posición fetal con un vaso campaniforme -estilo ILV- cerca del cráneo, además de más fragmentos y restos óseos desperdigados por la cámara. El segundo es Etxauri, del que se desconoce la localización exacta, bajo este topónimo se engloban de una manera muy imprecisa hallazgos dispares de diferentes cuevas y covachos (Barandiarán y Vallespí, 1980: 139). Gracias a una antigua fotografía (Fig. 8, n.o 7) se sabe que había al menos seis fragmentos (Barandiarán y Vallespí, 1980: 194), aunque algunos autores citan únicamente tres (Apellániz, 1973: $141)^{4} \mathrm{y}$, actualmente, en el Depósito de Materiales Arqueológicos del Gobierno de Navarra solamente se conserva uno.

\section{Materiales y método}

Tras una descripción tecnotipológica de los fragmentos y su decoración, se realiza una medición del tamaño de las impresiones y su separación, tratando las fotografías cenitales mediante un programa informático de fotometría. Se despieza la estructura decorativa, buscando similitudes entre puntos de distintas líneas. Con esto obtenemos una secuencia, es decir, una sucesión de improntas que se corresponden con las púas de la herramienta. Estas secuencias no necesariamente empiezan o terminan en el mismo punto, pero permiten medirlas de un extremo al otro.

\subsection{Los Husos I (Laguardia, Álava)}

- Un fragmento de galbo -LHI.C3.189.7 con $18,7 \times 16,7 \times 6 \mathrm{~mm}-$, que muestra fracturas mixtas

4 Cf. también Armendáriz, A.: Las cuevas sepulcrales del País Vasco. Tesis doctoral inédita presentada en 1992 en la Univ. del País Vasco. 
-tanto rectas, como en bisel-. La cocción es mixta con tonos anaranjados en ambas paredes y oscuros en el centro de la sección, la pasta contiene desgrasantes de pequeño tamaño. Mediante la observación a través de la lupa binocular, se ha podido determinar que el modelado de la pieza se llevó a cabo mediante el montaje de rollos. Las uniones de los mismos se disponen en 's' o ' $z$ ' internas. En relación al acabado, se observa que ha perdido casi todo el bruñido (Fig. 4, arriba). Apellániz, en su monografía, lo describe como un fragmento con "decoración de bandas a base de impresiones de punta seca de sección cuadrada separadas entre sí por zonas lisas" (1974: 86), pero no lo identifica como campaniforme puntillado (Fig. 3) $)^{5}$.

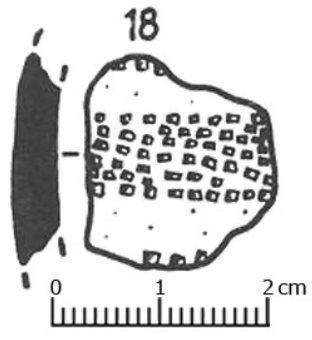

Fig. 3. Representación gráfica de LHI.C3.189.7 por Apellániz (1974: 85).

El fragmento presenta dos líneas horizontales de impresiones de sección cuadrangular paralelas y rellenas totalmente por puntillados oblicuos en caída hacia la derecha, con una inclinación entre 15 y 20 grados respecto a la banda horizontal (Fig. 4, arriba). Podemos distinguir siete líneas de puntillados oblicuos, ninguna completa. Las líneas están separadas por una franja de unos $0,5 \mathrm{~mm}$, aunque en algunos casos esta se va haciendo cada vez más estrecha hacia la parte inferior, llegando a solaparse entre las líneas 4-5 y 7-8. La anchura total de esta banda es de $10 \mathrm{~mm}$. Este friso está delimitado tanto por encima como por debajo por una cenefa lisa, la superior de 3,6 $\mathrm{mm}$ y la inferior de 2,8 $\mathrm{mm}$, tras lo cual hay otra línea de puntillados horizontales, que se aprecian parcialmente, pues la pieza se halla fracturada sobre esa línea tanto en la parte superior como en la inferior.

5 La orientación de la pieza que muestra Apellániz difiere de la que se propone en este trabajo que, tras analizar el fragmento, creemos que es la correcta.
- Un fragmento de galbo -LHI.F4.9.280.186 con 14 x 18 x 6,5 mm-, que tiene cocción mixta, con pastas finas y algunos cuarzos como desgrasantes de muy pequeñas dimensiones. Se pueden observar marcas de bruñido en la cara externa (López de Ocáriz, 2014: 30). El análisis tecnológico determinó que su confección se llevó a cabo mediante rollos montados de forma vertical-estratificada en forma de 's' o 'z' (Fig. 4, abajo).

En este fragmento se puede observar una línea horizontal de impresiones cuadradas sobre la que se disponen unas líneas oblicuas en caída hacia la izquierda -al contrario que en el primer fragmento-, con un ángulo de entre 22 y $25^{\circ}$ respecto a la línea horizontal (Fig. 4, abajo). Se conservan cuatro líneas de puntos oblicuas, tres de ellas con 8 impresiones y la última con 5. Bajo esto se encuentra una banda horizontal lisa de 2,8 $\mathrm{mm}$ de anchura -misma anchura que la franja inferior del primer fragmento-, bajo la cual se observa otra línea horizontal.

Si descomponemos las líneas decorativas y las montamos en horizontal una sobre otra, con el fin de comparar las impresiones, se puede ver que estas son aproximadamente de 1 x $1 \mathrm{~mm}$, con una separación entre cuadrados de unos $0,5 \mathrm{~mm}$, formando una serie de $22 \mathrm{~mm}$ de longitud y 15 puntos $-\mathrm{A}$, B, C..., M, N, O- (Fig. 4). Se puede observar que en todos los casos la serie empieza por la A, cuidándose de presionar menos el primer punto, para no pisar o desdibujar la línea de puntos horizontal realizada previamente. Al final de la secuencia también podemos observar este fenómeno, estando los puntos $\mathrm{N}$ y o menos marcados. El final de la secuencia en dos de las líneas está en el punto $\mathrm{M}$.

Primero se realiza una banda con las dos líneas horizontales, delimitando la anchura de la cenefa de líneas oblicuas, que adaptarán su inclinación a esta anchura. En el caso de la primera pieza la anchura total de la banda es de $10 \mathrm{~mm}$ y la separación entre las dos líneas de puntos que la delimitan de $7,5 \mathrm{~mm}$. En el segundo fragmento no se conserva la anchura total de la banda de puntillado, pero probablemente fuese algo más ancha que la anterior, puesto que el grado de inclinación de las líneas oblicuas es mayor. 

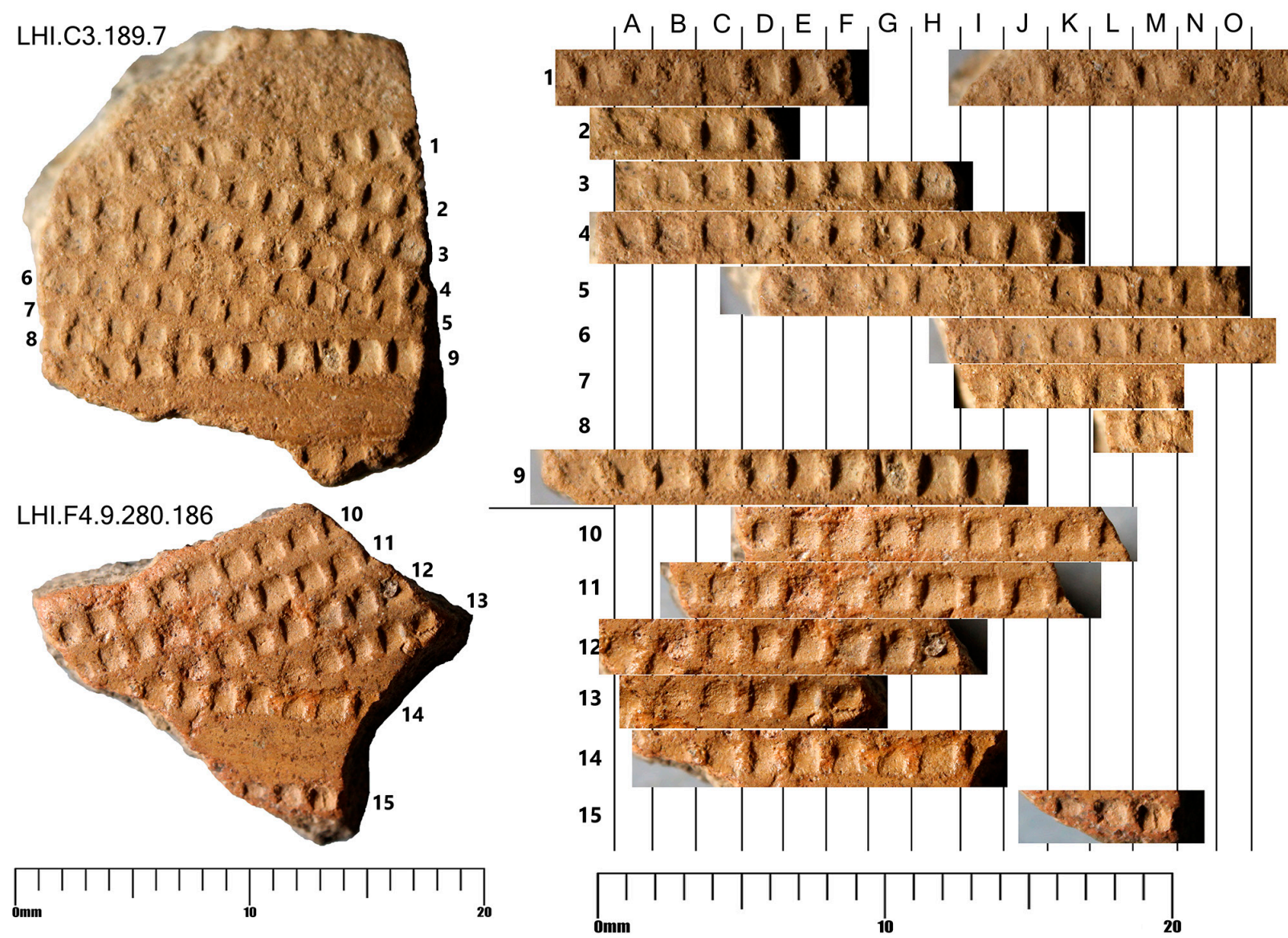

Fig. 4. Los dos fragmentos campaniformes de Los Husos I (izda.) y despiece de la decoración de los dos fragmentos (dcha.).

En la línea 1 se superponen dos secuencias, primero se realizó la parte de la derecha, de la que se conserva la secuencia A-F y posteriormente la de la izquierda, donde podemos ver la secuencia I-O. Lo destacable en este caso es que, al realizar la segunda serie, los últimos puntos de la secuencia $-\mathrm{N}$ y O- se superpusieron sobre los dos primeros de la secuencia anterior -A у в-, desdibujándolos. Este hecho nos muestra que el trazado de líneas horizontales se hizo de derecha a izquierda.

Observando las anchuras, tanto de las impresiones como del espacio entre ellas y el orden que siguen, junto con algunos 'errores' dentro de la decoración, se ve que todos los puntos no son totalmente iguales. Los más identificativos son los puntos D, G, H, J, y M. El D es más estrecho que el resto; el G tiene una marca en la parte superior; el H es más ancho que el resto; el $\mathrm{J}$ es trapezoidal, y el $\mathrm{M}$ tiene una marca vertical. Estas taras o diferencias se repiten en todas las secuencias, lo que nos indica que todas las líneas -de ambas piezas- se realizaron con la misma herramienta: un peine de alfarero o gradina fabricado, probablemente, en hueso o madera, con 15 dientes y unas medidas de $22 \mathrm{~mm}$ de longitud y $1 \mathrm{~mm}$ de ancho.

\subsection{Trikuaizti I (Beasain, Guipúzcoa)}

- Un vaso, del que se conservan un perfil reconstruido, 17 fragmentos determinables -12 del cuello, 3 bordes y 2 galbos- y 28 fragmentos pequeños. Mide $144 \mathrm{~mm}$ de altura, $100 \mathrm{~mm}$ de diámetro de borde interior, $108,5 \mathrm{~mm}$ en el exterior, $86 \mathrm{~mm}$ de diámetro del fondo plano y tiene $827 \mathrm{cc}$ de capacidad. El borde es redondeado simple y el grosor 
de las paredes varía entre 4 y 5 mm. La cocción es mixta con tonos anaranjados en las paredes y oscuros en el interior, la pasta es fina y depurada, apenas se aprecian inclusiones de visu. Este recipiente se realizó mediante la técnica de superposición de columbinos y debido al lugar y tipo de fracturas se puede comprobar que son seis los rollos y miden entre 26 y $29 \mathrm{~mm}$ de anchura. En algunas zonas del recipiente todavía se observa el bruñido de las paredes. Su decoración es de estilo CZM (Fig. 9, n. ${ }^{\circ}$ 8).

La decoración del vaso se compone de seis bandas decoradas mediante líneas puntilladas oblicuas de dirección alternante. Las bandas están delimitadas por una línea única de cuerda, de torsión en 'z' (Salanova, 2000: 31) (Fig. 12, n.o 2), a excepción de la línea superior de la primera banda y la inferior de la última, que están realizadas mediante puntillado. Por lo tanto, el vaso tiene diez líneas horizontales cordadas, enmarcadas entre dos puntilladas. La decoración empieza a diez milímetros del labio, con el primer friso con caída hacia la derecha con una inclinación de 30-350 sobre la línea horizontal, las líneas están separadas por una estrecha franja de unos $0,3 \mathrm{~mm}$, teniendo cuidado de no solaparse
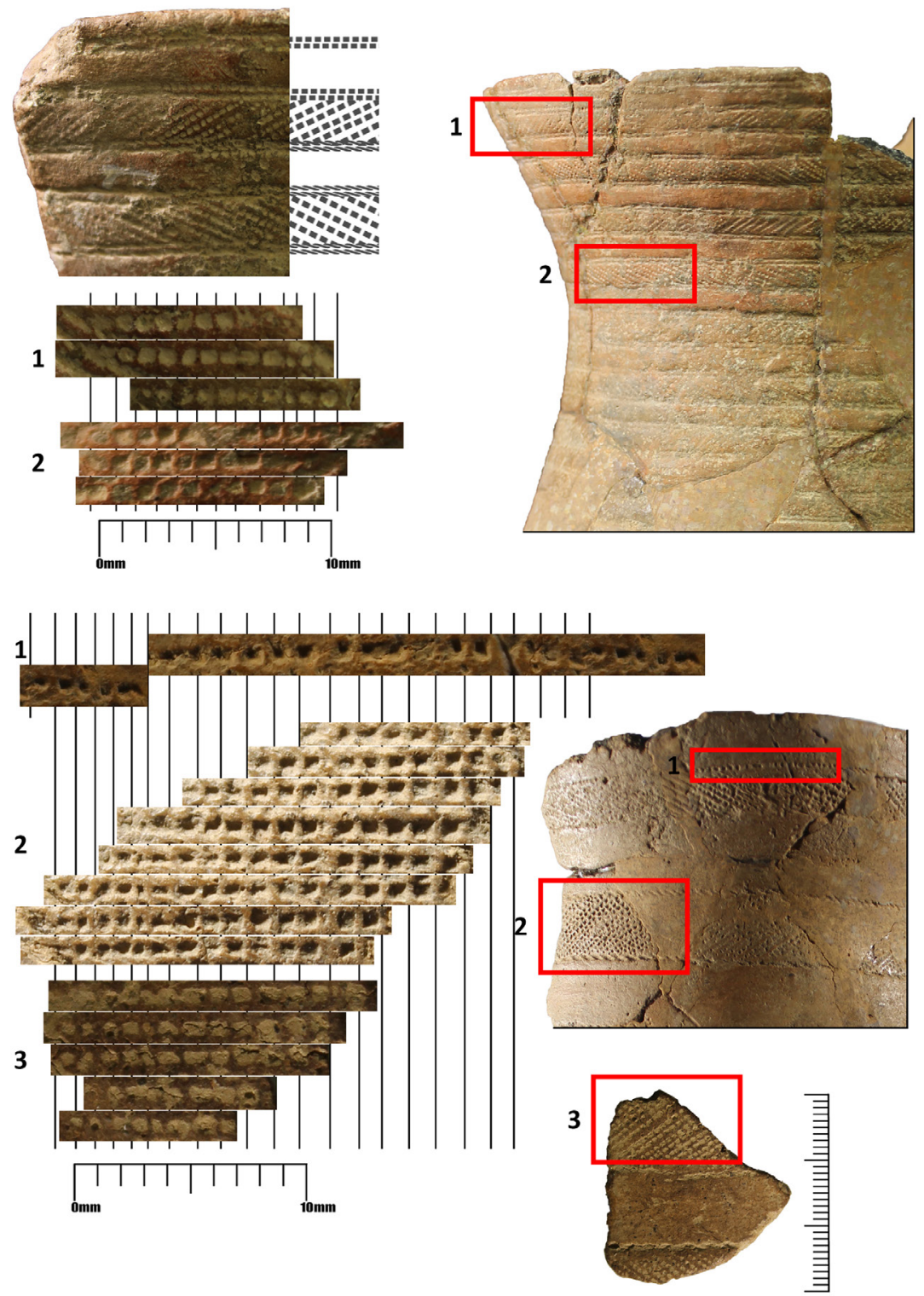

Fig. 5. Despiece de la decoración y detalle del borde con líneas horizontales de puntillado y de cuerda del vaso de Pagobakoitza (Sierra de Aizkorri, Guipúzcoa) (arriba) y despiece de la decoración del vaso y fragmento de Trikuaizti I (Beasain, Guipuzcoa) (abajo). en ningún momento.

El primero de los frisos es el más estrecho, de tan solo $7 \mathrm{~mm}$, siendo el resto de entre 11 y $12 \mathrm{~mm}$. Los espacios lisos tienen entre 10 y $12 \mathrm{~mm}$ de anchura. Las impresiones de este vaso tienen forma cuadrada con un tamaño de 0,5-0,7 x 0,5 mm y una separación entre puntos de $0,3 \mathrm{~mm}$.
Se ha realizado el despiece de una de las bandas decorativas del vaso y de uno de los fragmentos mejor conservados, observándose una secuencia de 19 puntos y $20 \mathrm{~mm}$. Pero al compararlos con la horizontal puntillada del borde -que es una línea larga donde se solapan distintas series de puntos- se 
obtiene una secuencia más larga de 23 puntos y 24 $\mathrm{mm}$, de lo que se deduce que en las líneas oblicuas no se ha utilizado el borde dentado completo de la herramienta (Fig. 5, abajo).

\subsection{Larrarte (Beasain, Guipúzcoa)}

- 67 fragmentos pertenecientes a un único recipiente, la gran mayoría no superan el centímetro de anchura y, por lo tanto, solamente se han estudiado los 13 -un borde y 12 galbosfragmentos mejor conservados $-11 \times 10 ; 15 \times$ 12,$5 ; 10 \times 10 ; 19 \times 9 ; 13 \times 12 ; 12,5 \times 9 ; 13 \times 10$; 10,5 x $11 ; 14$ x $13 ; 12$ x 9,5; $15,5 \times 12 ; 8 \times 7 ; 11 \times$ 8 , con un grosor variable entre 3,5 y $4 \mathrm{~mm}-$. La cocción es mixta con coloraciones anaranjadas en el exterior de las paredes y negruzcas en el centro, aunque algunos fragmentos han perdido la coloración naranja. Las pastas parecen finas con abundantes inclusiones, pero de pequeño tamaño. Algunos fragmentos conservan partes de su superficie bruñida, sin embargo, ha sido imposible identificar la técnica del modelado. El recipiente está decorado con dos técnicas distintas - el puntillado y el cordado- y se enmarca dentro del estilo CzM (Fig. 9, n. ${ }^{\circ}$ 6).

A pesar del pequeño tamaño de los materiales se observa que la decoración de este vaso está formada por bandas de puntillado oblicuo en dirección alternante enmarcada entre dos líneas cordadas. En las bandas lisas también hay otra línea cordada intermedia, como en el estilo ILV, pero con cuerda. El sentido de la torsión de la cuerda varía -en 's' y en ' $z$ '-, pero es el mismo dentro de los grupos de líneas. Este cambio en el sentido de la torsión indica el uso de al menos dos cuerdas distintas. La anchura de los frisos con impresiones oblicuas es de entre 5,5 y $8 \mathrm{~mm}$ y la de las bandas lisas intermedias de 1,5 y 2,3 mm. Los puntos tienen forma cuadrangular y un tamaño de $0,7 \mathrm{x}$ $0,7 \mathrm{~mm}$, con una separación de $0,2 \mathrm{~mm}$. La caída es de entre $29-32^{\circ}$ en algún fragmento y de entre 36-39o en otros. Debido al estado de conservación de los fragmentos no es posible realizar el despiece de las líneas de la decoración.

\subsection{Pagobakoitza (Sierra de Aizkorri, Guipúzcoa)}

- Perfil completo que mide $184 \mathrm{~mm}$ de altura, $150 \mathrm{~mm}$ de boca exterior, 138 de interior y tiene una capacidad de $1558 \mathrm{cc}$. El fondo es umbilicado y el borde redondeado y simple. El grosor de las paredes es de $5 \mathrm{~mm}$ y la cocción de la pasta es mixta con tonos anaranjados en ambos exteriores y negro en el interior. La fabricación del vaso se realizó mediante la superposición de rollos, cuyas marcas de cosido se observan en la cara interna del recipiente y en las fracturas. La conservación de las superficies es desigual, en algunas zonas se pueden observar nítidamente las impresiones de la decoración, mientras que en otras apenas se reconocen las franjas y se ha perdido incluso la parte anaranjada de las paredes (Fig. 9, n.o 7).

La decoración del vaso es del tipo CzM y está compuesta de 15 bandas de puntillado oblicuo en dirección alternante. Comienza con dos líneas horizontales, paralelas y juntas de puntillado a $2,5 \mathrm{~mm}$ del borde, bajo esto y a $3,5 \mathrm{~mm}$ hay una cenefa de puntillado oblicuo en caída hacia la izquierda, delimitada en la parte superior por otras dos líneas de puntillado horizontal, paralelas y juntas y dos líneas cordadas en la inferior (Fig. 5, arriba). El resto de las bandas están delimitadas por dos líneas de cuerda impresa, con sentido de torsión en z. Las bandas puntilladas tienen una anchura interior de entre 4 y 5,5 mm, además de las dobles líneas de cuerdas superior e inferior de $2 \mathrm{~mm}$ cada una, y las bandas lisas son de entre 3,5 y $4,5 \mathrm{~mm}$. Las impresiones son cuadrangulares, de 0,6-0,7 x 0,6 mm, con una separación de apenas $0,1 \mathrm{~mm}$. El ángulo de la caída no varía mucho entre las diferentes bandas y se sitúa entre 27-33 grados. Tras el despiece de líneas, podemos observar que están formadas por una secuencia de 12 puntos y $11 \mathrm{~mm}$ de largo (Fig. 5, arriba).

- Fragmento de galbo de otro vaso $-32 \times 34$ y $5 \mathrm{~mm}$ de grosor- que posiblemente pertenezca a la parte superior del cuerpo justo por debajo del inicio del cuello. Se trata de una cocción mixta con las paredes anaranjadas y el interior negruzco, la pasta es muy fina y las inclusiones son escasas y pequeñas. No es posible identificar tratamiento de 

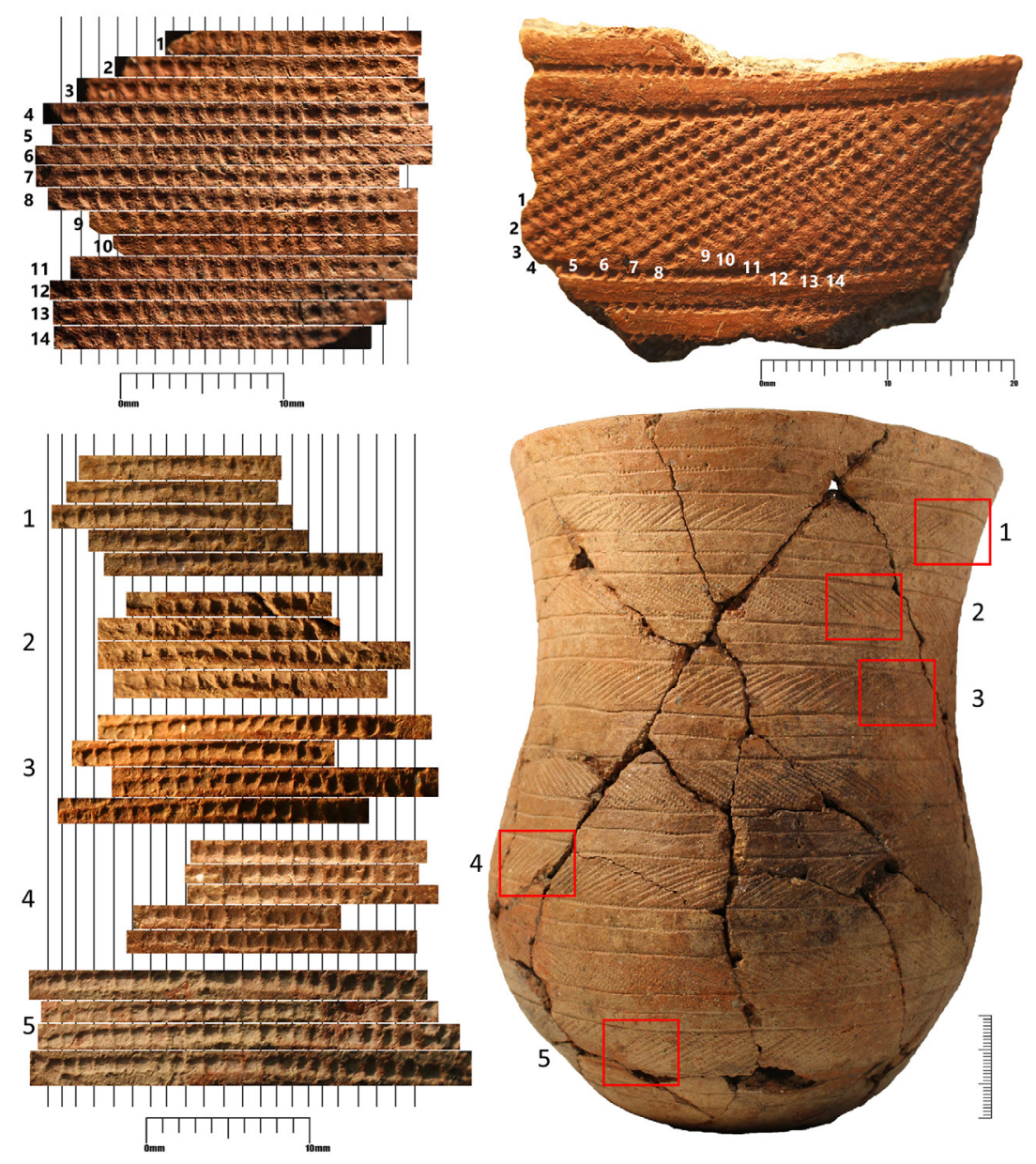

Fig. 6. Despiece de la decoración del fragmento de Etxauri (Etxauri, Navarra) (arriba) y del vaso completo de Tres Montes (Bardenas Reales, Navarra) (abajo).

banda son más estrechas $-0,4$ $0,6 \times 0,6 \mathrm{~mm}-$, más separadas $-0,3 \mathrm{~mm}-\mathrm{y}$ menos nítidas que las improntas del centro, que son más anchas $-0,7-0,9 \times 0,6$ $\mathrm{mm}-\mathrm{y}$ con menor separación $-0,1-0,2 \mathrm{~mm}-$. Este gesto de presionar más en el centro que en los extremos se debe, posiblemente, al cuidado de no pisar las líneas horizontales. Debido al estado de conservación no se ha podido hacer el despiece de las improntas.

\subsection{Gorostiaran Este (Sierra de Aizkorri, Guipuizcoa)}

- Cuatro fragmentos -21 x 22; 16 x 25; 22 x $18 ; 11$ x 24 con $4 \mathrm{~mm}$ de grosor-, que son un borde y 3 galbos. El borde es redondeado simple y tiene un diámetro de $154 \mathrm{~mm}$. La cocción es mixta, con las paredes de tonos anaranjados y el cuerpo negro; la pasta es fina, con pequeñas inclusiones. Los cuatro fragmentos están muy

la superficie, sin embargo, sí hemos podido comprobar que este recipiente se realizó mediante la técnica de superposición de churros o rollos. En cuanto a la decoración se trata al igual que el vaso anterior de un ejemplar de CzM (Fig. 9, n.o 5).

Presenta una decoración compuesta por cuatro bandas, la primera, lisa de $7 \mathrm{~mm}$, sobre una cenefa decorada con puntillado de $9 \mathrm{~mm}$, con caída hacía la derecha entre 25 y 29\%, delimitada por dos líneas cordadas paralelas con sentido de torsión en z. La siguiente banda tiene dos líneas cordadas paralelas en el centro de la cenefa con un grosor de $8 \mathrm{~mm}$ $y$, por último, se observa el comienzo de una banda puntillada hacia la izquierda. Se puede observar que las improntas más cercanas a los extremos de la deteriorados y ha desaparecido cualquier huella de un posible tratamiento de las superficies. La decoración de este recipiente es de estilo CZM (Fig. 9, n.o 2).

La decoración del vaso está compuesta por bandas de puntillado oblicuo de dirección alternante enmarcadas entre una línea impresa de cuerda -de torsión en ' $z$ '-. La decoración comienza a $6 \mathrm{~mm}$ del labio con una banda de puntillado oblicuo en caída hacia la derecha entre 20 y $27^{\circ}$. La anchura de la primera banda decorada es de $6 \mathrm{~mm}$ y de 8 $\mathrm{mm}$ en otro de los fragmentos. La banda lisa tiene $9 \mathrm{~mm}$. El deficiente estado de conservación impide realizar cualquier medición de las impresiones puntilladas. 


\subsection{Etxauri (Etxauri, Navarra)}

- Fragmento de galbo $-44 \times 28 \times 6 \mathrm{~mm}-$ perteneciente a un vaso que tenía $11 \mathrm{~cm}$ de diámetro en esta zona; su cocción es mixta, con tonos anaranjados en la superficie externa y tendente a negros en la cara interna. La superficie de la pared externa está bruñida. La decoración es del tipo ILV (Fig. 8, n.o 6).

La decoración del vaso se compone de franjas de puntillado oblicuo en dirección alternante y franjas en blanco con tres líneas de puntos paralelas. Debido a un error de dibujado y descripción de la pieza, en varias ocasiones se ha señalado como de líneas puntilladas no alternantes (Apellániz, 1973: 141; Rodanés, 1992: 600).

El fragmento conservado presenta un friso central, completamente relleno de líneas puntilladas oblicuas inclinadas hacia la izquierda, con una pendiente de $27-30^{\circ}$ sobre la línea horizontal. Las líneas oblicuas están muy juntas, apenas separadas entre sí por $0,3 \mathrm{~mm}$, algunas incluso superponiéndose. El friso central tiene una anchura de $13 \mathrm{~mm}$, mientras que los frisos lisos que tiene tanto en la parte superior como inferior, separados por líneas puntilladas horizontales, no conservan la anchura completa. Basándonos en la fotografía antigua (Barandiarán y Vallespí, 1980: 194) se observa que en las cenefas lisas hay tres líneas horizontales puntilladas que separan cuatro franjas lisas finas, con una anchura completa de entre 10,5 y $11,5 \mathrm{~mm}$, mientras que las bandas intermedias tienen una anchura de entre 2,5 y $3,5 \mathrm{~mm}$. Las impresiones puntilladas de esta pieza tienen forma cuadrada con un tamaño de 0,8 x $0,8 \mathrm{~mm}$, mientras que la separación entre los puntos es de entre 0,2-0,4 mm. Si realizamos el trabajo de despiece de las líneas de puntos en el fragmento conservado, podemos ver una secuencia de 19 puntos en $22 \mathrm{~mm}$ (Fig. 6, arriba).

\subsection{La Mina (Molinilla, Álava)}

- Siete fragmentos de galbo - $18 \times 14 ; 18 \times 12$; $22 \times 12 ; 14 \times 14 ; 12 \times 22 ; 29 \times 32$, con un grosor de $5,5 \mathrm{~mm}-$. La cocción de este vaso es mixta con tonos anaranjados en ambas paredes y pasta negra en el centro. El pequeño tamaño y la deficiente conservación imposibilitan identificar algún tratamiento de las superficies. La decoración de este vaso es de la variante MHV (Fig. 8, n. ${ }^{\circ} 2$ ).

El fragmento de mayor tamaño presenta dos frisos bien diferenciados, el superior está completamente relleno de líneas puntilladas oblicuas en caída hacia la izquierda, con una inclinación de entre 28-31 sobre la línea horizontal. Las líneas oblicuas están separadas entre sí por una franja irregular de entre 0,3 y $1,5 \mathrm{~mm}$ de grosor. El fragmento se encuentra roto en su parte superior, parece que por la línea horizontal que cierra la banda de líneas oblicuas, pero este extremo no se puede confirmar debido a que no se observan improntas de la citada línea horizontal. Suponiendo que así fuere, la banda tendría una anchura de $12 \mathrm{~mm}$. Bajo esa banda puntillada, se observa otra sin decoración y bajo ella el arranque de otra banda puntillada, con una línea de puntos horizontal y las líneas oblicuas en caída hacia la derecha. Tanto en ese fragmento, como en otro de menor tamaño, se pueden medir dos cenefas lisas, de 11,3 y 11,2 mm de anchura. Por último, las impresiones puntilladas de esta pieza tienen forma rectangular y presentan un tamaño de 1,2-1,5 x 0,5 $\mathrm{mm}$, mientras que la separación entre los puntos es de entre 0,3 y $0,5 \mathrm{~mm}$.

\subsection{La Atalayuela (Agoncillo, La Rioja)}

- Fragmento de galbo -23 x 20 y $4 \mathrm{~mm}$ de grosor- perteneciente al cuello del vaso. La cocción es mixta con las paredes anaranjadas y el centro negro. Presenta inclusiones de pequeño tamaño y entre ellas se distinguen algunos cuarzos. Se aprecian restos de un bruñido que en la mayor parte de la superficie se ha perdido. La decoración de este recipiente es de estilo CZM. Actualmente está cortado mediante sierra mecánica en la parte superior para algún tipo de análisis del que no se ha publicado ningún resultado (Fig. 9, n. ${ }^{\circ} 1$ ).

La decoración se compone de franjas lisas y otras decoradas con puntillado oblicuo de dirección alternante. El fragmento conserva la anchura 
completa tanto en el friso superior liso como en el inferior, con puntillado oblicuo descendente hacia la derecha con una inclinación de entre 39-41\%. Ambos están delimitados por dos impresiones cordadas, con torsión en ' $z$ ' y la anchura de los mismos es de $11 \mathrm{~mm}$. Las impresiones puntilladas tienen forma cuadrangular y presentan un tamaño muy pequeño de $0,4 \times 0,4 \mathrm{~mm}$, mientras que la separación entre los puntos es de entre 0,1 y $0,2 \mathrm{~mm}$. No ha sido posible realizar el despiece de la decoración.

\subsection{Túmulo IL. Cl (Cotar, Burgos)}

- Tres fragmentos de galbo $-24 \times 23 ; 10 \times 12$; 18 x 16 y $4 \mathrm{~mm}$ de grosor- pertenecientes al mismo recipiente, de los cuales el mayor podría ser parte del cuello del vaso. La cocción es irregular y se observa alguna inclusión de cuarzo. Su erosión impide atisbar cualquier tratamiento de las superficies (Fig. 8, n.o 4).

La decoración del vaso se compone de bandas de puntillado oblicuo en dirección alternante -estilo MHV-. En el fragmento de mayor tamaño se

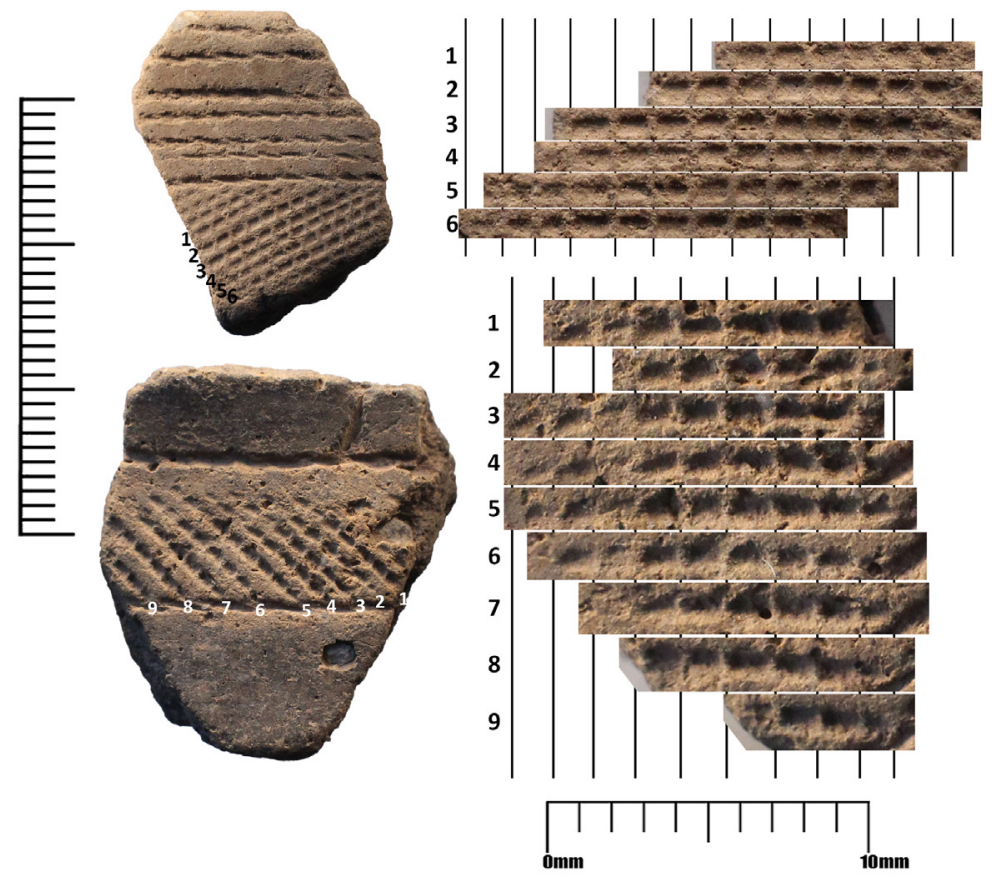

FIG. 7. Despiece de la decoración del fragmento de borde (arriba) y fragmento de galbo (abajo) de El Castillo (Burgos). observan tres frisos bien diferenciados, el superior es liso, tiene entre 8 y $8,5 \mathrm{~mm}$ de anchura y está delimitado por líneas de puntos horizontales. El central tiene una anchura de entre 8,5 y $9 \mathrm{~mm}$ y está completamente relleno de líneas puntilladas oblicuas en caída hacia la derecha, con un ángulo de 20-240 sobre la línea horizontal. Las líneas oblicuas están separadas por una franja irregular de entre 0,3-0,5 $\mathrm{mm}$ de grosor. Las impresiones tienen forma cuadrada y un tamaño de $0,8 \times 0,8$ $\mathrm{mm}$, mientras que la separación entre los puntos es de aproximadamente $0,3 \mathrm{~mm}$. La degradación de las superficies hace imposible el despiece de las decoraciones. Bajo este friso arranca otro liso, que se halla incompleto.

\subsection{El Castillo (Burgos)}

- Siete fragmentos de galbo $-18 \times 11 ; 18 \times 16$; 19 x 19; 17 x 19; 16 x 11; 20 x 18; 15 x 11 y entre 4 y 5 $\mathrm{mm}$ de grosor-, dos de ellos pertenecientes al cuello del recipiente y otro al arranque del fondo. La cocción es irregular y se observan inclusiones de cuarzo y mica. La conservación general es bastante deficiente, lo que hace imposible ver cualquier tratamiento de las superficies (Fig. 8, n.o 3).

La decoración del vaso se compone de bandas de puntillado oblicuo de dirección alternante y una línea de puntos horizontal en las bandas lisas - estilo ILV-. Solo en uno de los fragmentos se conserva la anchura completa de un friso puntillado $-11 \mathrm{~mm}-$, en caída hacia la derecha, con un ángulo de 40$45^{\circ}$ sobre la línea horizontal. En otros fragmentos la inclinación es menor, de entre 28-32\%. La separación entre las líneas oblicuas es de entre 0,5 y 0,8 $\mathrm{mm}$. La banda lisa tiene una anchura variable entre 7 y $9,5 \mathrm{~mm}$, separada horizontalmente por una línea de puntillados, siendo las bandas estrechas de entre 3,5 y 4,5 mm. Las impresiones 

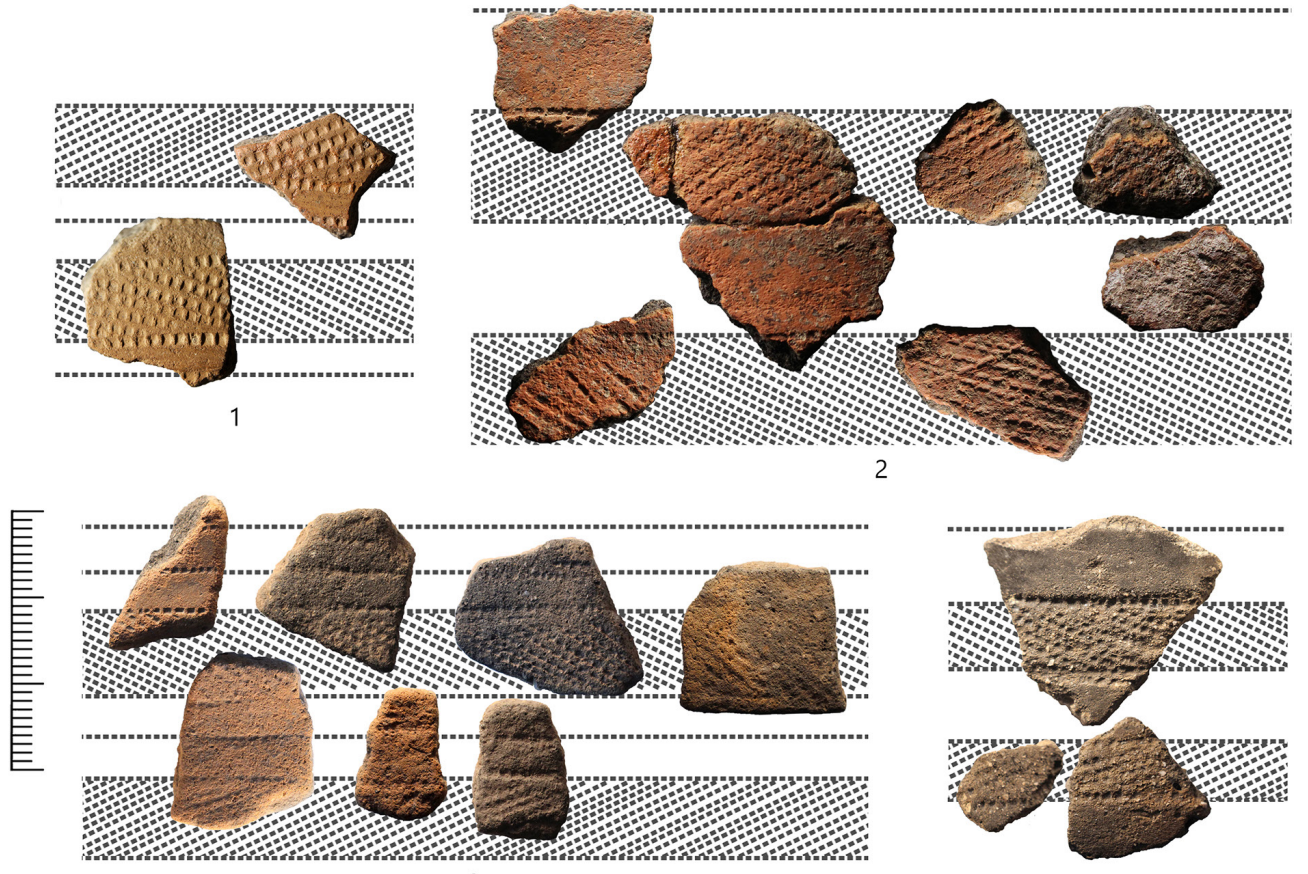

3
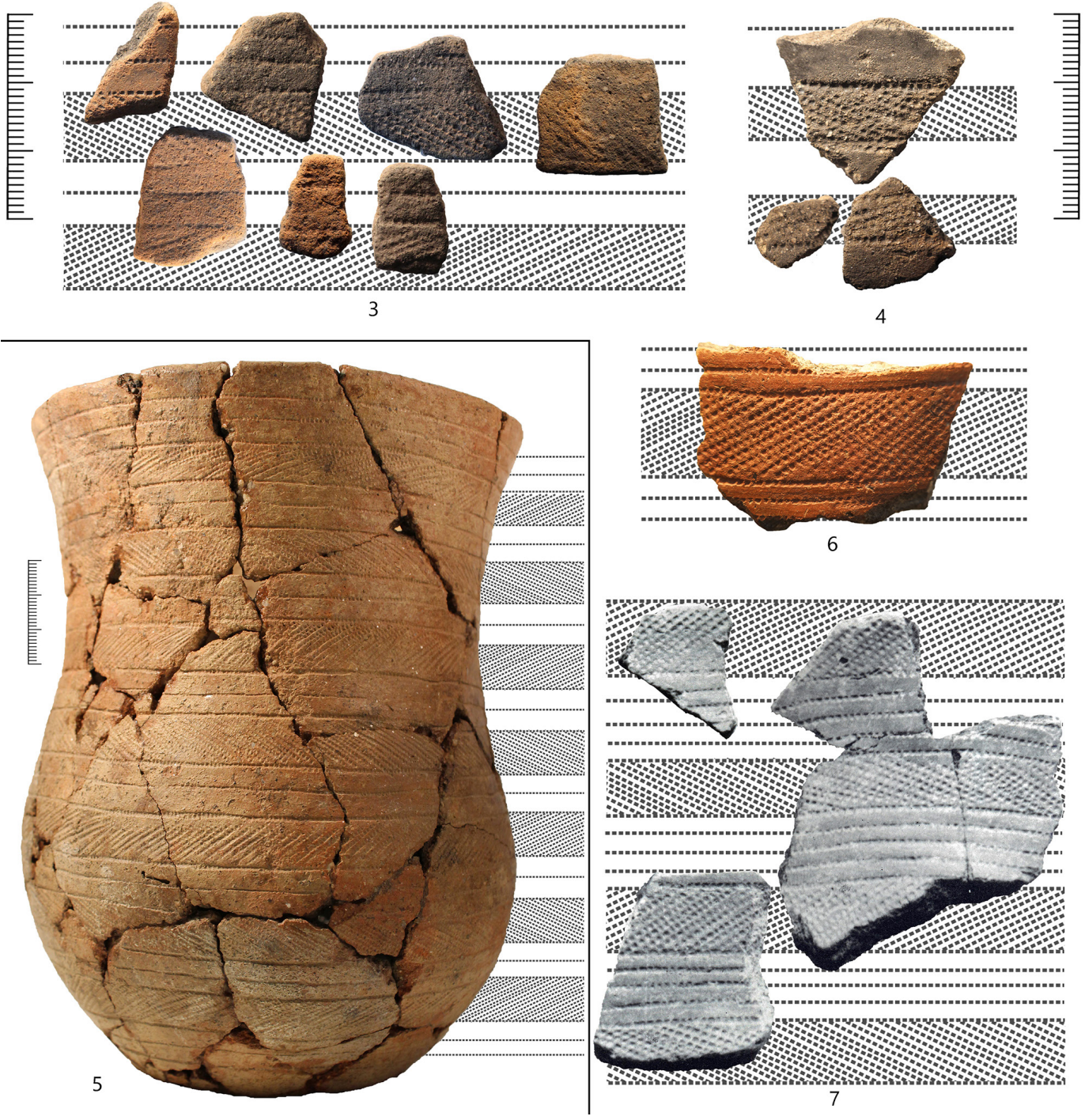

FIG. 8. Representación de todos los fragmentos de vasos campaniformes marítimos - estilos MHV o ILV-analizados en este trabajo: 1) Los Husos I (Laguardia, Álava); 2) La Mina (Molinilla, Álava); 3) El Castillo (Burgos); 4) Túmulo IL.C1 (Cótar, Burgos); 5) Tres Montes (Bardenas Reales, Navarra); 6-7) Etxauri (Etxauri, Navarra) (fragmento conservado y fragmentos desaparecidos según Barandiarán y Vallespi, 1980: 194). 
puntilladas tienen forma rectangular y presentan un tamaño de 0,9 x 0,4-0,5 mm, mientras que la separación entre los puntos es de entre 0,2-0,3 $\mathrm{mm}$. La deficiente conservación hace imposible realizar los despieces de las impresiones.

- Fragmento de borde -24 x 15 y $4 \mathrm{~mm}$ de grosor- redondeado simple. Tiene las pastas muy finas y con pequeñas inclusiones, la cocción es mixta con tonos marronáceos en el exterior y negros en el interior. Se observan restos del bruñido. La decoración es de estilo CZM (Fig. 9, n. ${ }^{\mathrm{o}}$ 4).

La decoración de este fragmento comienza a un milímetro del borde con una línea cordada, a la que le siguen seis más - paralelas-, todas con torsión en ' $z$ ' y una separación entre 0,5 y $2 \mathrm{~mm}$. La banda puntillada oblicua mide $8,5 \mathrm{~mm}$ de anchura con caída hacia la izquierda de entre 25 y 29 grados. Las líneas están bien marcadas y separadas entre sí por espacios lisos de $0,3 \mathrm{~mm}$ de anchura, los puntos son rectangulares de $0,8 \times 0,5 \mathrm{~mm}$ y una separación de 0,25 mm. Tras el despiece de la decoración, se puede observar que está formada por secuencias de $15 \mathrm{~mm}$ y 13 puntos (Fig. 7, arriba).

- Tres fragmentos de un mismo recipiente $-23 \times 25 ; 23,5 \times 26 ; 23$ × 27 y un grosor de 7 $\mathrm{mm}-$. La cocción es irregular y se distinguen tonalidades que van desde un gris claro a un negro. Las pastas no son finas y las inclusiones son abundantes y de tamaño mediano. Debido al estado de conservación desconocemos el tratamiento de las superficies. Está decorado con estilo CZM (Fig. 9, n. ${ }^{\circ}$ 3).

Aunque todos los fragmentos pertenecen a bandas diferentes, tienen en común la caída hacia la derecha, con un ángulo entre $42-46^{\circ}$ y $51-55^{\circ}$. Si como en el resto de los casos estas bandas fuesen alternantes, este recipiente tendría al menos cinco bandas decoradas. La anchura tanto de las bandas lisas como de las decoradas se sitúa entre 8,5 y 9,5 mm y están delimitadas por impresiones cordadas con torsión en ' $z$ '. Las impresiones son rectangulares, de 1 x 0,6 mm y una separación de 0,2 $\mathrm{mm}$. Tras el despiece de la decoración, se puede observar que está formada por secuencias de $12 \mathrm{~mm}$ y 9 puntos (Fig. 7, abajo).

(C) Universidad de Salamanca

\subsection{Tres Montes (Bardenas Reales, Navarra)}

- Perfil completo que mide $185 \mathrm{~mm}$ de altura, $120 \mathrm{~mm}$ de boca y $1516 \mathrm{cc}$ de capacidad. La forma de las paredes nos sugiere un perfil más esbelto que el de otros ejemplares completos conservados en la Península Ibérica. El grosor de las paredes es de $5 \mathrm{~mm}$ y la cocción de la pasta es mixta con tonos anaranjados en ambos exteriores y negro en el interior. La fabricación del vaso se realizó mediante la superposición de rollos, cuyas marcas de cosido se observan en la cara interna del recipiente. La conservación de las superficies es desigual, hay algunas zonas que han sufrido desconchados, pero en otras aún se conserva el fino bruñido que seguramente sería algo extensivo a todo el recipiente (Fig. 8, n. ${ }^{\circ}$ 5).

La decoración del vaso se compone de quince bandas delimitadas por líneas horizontales puntilladas, y responde al patrón decorativo de la variedad ILV, alternándose bandas con rellenos completos de líneas oblicuas con otras que únicamente cuentan con una línea horizontal en el medio. La decoración empieza a 7,5 $\mathrm{mm}$ del labio, con una línea puntillada, bajo la cual hay otra a $5 \mathrm{~mm}$, posteriormente, el primer friso relleno de puntillados oblicuos. El vaso presenta siete bandas oblicuas intercaladas entre bandas lisas con línea puntillada horizontal en el medio. Las bandas de puntillados oblicuos van alternando la dirección de caída, siendo la primera hacia la izquierda, con una inclinación de 30-35 sobre la línea horizontal. Esta inclinación no es constante en todo el vaso, variando desde los $25-29^{\circ}$ del segundo friso hasta los 37-43 del tercero. La separación entre las líneas puntilladas oblicuas es irregular, algunas separadas hasta por $1 \mathrm{~mm}$ mientras que otras se superponen. La anchura tanto de los frisos decorados como de los lisos varía entre los 10 y los $12,5 \mathrm{~mm}$, las cenefas lisas cuentan con una línea horizontal puntillada que las divide en dos bandas más estrechas de entre 4,5 y $6 \mathrm{~mm}$. Las impresiones de este vaso tienen forma cuadrada, con un tamaño de 0,9 x 0,9 mm y una separación muy fina de entre 0,1 y $0,2 \mathrm{~mm}$.

La conservación de esta pieza hace posible el despiece de las decoraciones que hemos realizado en 

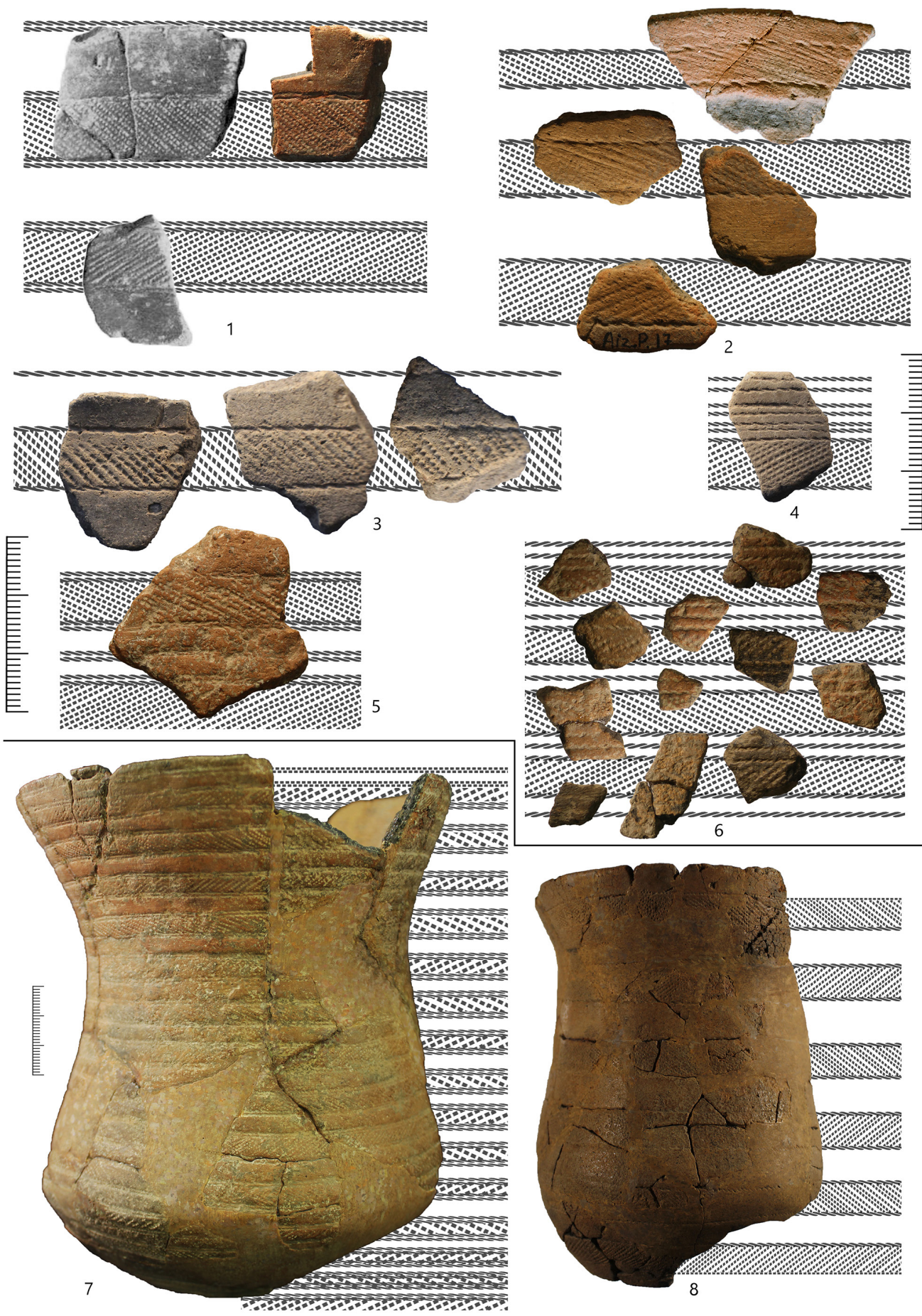

FIG. 9. Representación de todos los fragmentos de vasos campaniformes marítimos -estilo CZM- analizados en este trabajo: 1) La Atalayuela (Agoncillo, La Rioja) (fragmento conservado y fragmentos desaparecidos según Barandiarán, 1978: lám. 3); 2) Gorostiaran Este (Sierra de Aizkorri, Guipüzcoa); 3-4) El Castillo (Burgos); 5 y 7) Pagobakoitza (Sierra de Aizkorri, Guipuzcoa); 6) Larrarte (Beasain, Guipuizcoa); 8) Trikuaizti I (Beasain, Guipúzcoa). 
distintas bandas. Se observa una serie de 22 puntos en $24 \mathrm{~mm}$ de longitud, aunque no se realiza la impresión completa de las líneas en todas las bandas, siendo en algunos casos solamente de 8 puntos en $12 \mathrm{~mm}$. Estas secuencias cortas/largas no se hallan intercaladas entre sí, sino que se encuentran agrupadas todas en el mismo friso o en tramos concretos de un friso (Fig. 6, abajo).

\section{Discusión}

Los vasos campaniformes suelen relacionarse con el consumo de bebidas alcohólicas durante la celebración de banquetes ceremoniales (Guerra, 2006: 69). La mayoría de los hallazgos se encuentran ligados al mundo funerario y precisamente son estos ejemplares los que tienen unos patrones decorativos más rígidos y repetidos con respecto a los que aparecen en los contextos domésticos (Salanova, 2001: 98). El ámbito de estudio de este trabajo no es una excepción; únicamente dos de los catorce ejemplares proceden de contextos no funerarios, Etxauri, que no tiene una procedencia segura, y Los Husos I, Capa IX, que se trata de un nivel de estabulación de ganado. A pesar de ser este último el único ejemplar estudiado recuperado en un contexto no funerario, también se han localizado

\begin{tabular}{|l|c|c|c|c|}
\hline \multicolumn{1}{|c|}{ Vasos } & Puntillados & Lisos & Liso intermedio & Variante \\
\hline Los Husos I & 10 & - & 3,1 & ILV \\
\hline Trikuaizti I & $11-12$ & $10-12$ & - & CZM \\
\hline Larrarte & $5,5-8$ & - & $1,5-2,3$ & CZM \\
\hline Pagobakoitza (1) & $8-9,5$ & $3,4-4,5$ & - & CZM \\
\hline Pagobakoitza (2) & 9 & $7-8$ & $3,5-4$ & CZM \\
\hline Gorostiaran Este & $6-8$ & 9 & - & CZM \\
\hline Etxauri & 13 & 11 & 3 & ILV \\
\hline La Mina & - & 11,2 & - & MHV \\
\hline La Atalayuela & 11 & 11 & - & CZM \\
\hline Túmulo IL.C1 & 8.5 & 8 & - & MHV \\
\hline El Castillo (1) & 11 & 9 & 4,5 & ILV \\
\hline El Castillo (2) & 8,5 & - & - & CZM \\
\hline El Castillo (3) & $8,5-9,5$ & $8,5-9,5$ & - & CZM \\
\hline Tres Montes & 11,1 & 10,7 & 5 & ILV \\
\hline
\end{tabular}

FIG. 10. Anchura media $(\mathrm{mm})$ de los frisos en los yacimientos estudiados y variante decorativa. campaniformes de estilo Internacional en poblados gallegos (Bonilla et al., 2006), meseteños (Garrido, 2000: 110) o del so peninsular (Cardoso, 2011; Cardoso et al., 2013; García Rivero et al., 2016: 17). Sin embargo, los hallazgos de campaniformes de estilos regionales son recurrentes en yacimientos calcolíticos con diferente funcionalidad. Cercanos al yacimiento de Los Husos I se han encontrado, además de en dólmenes, en el Abrigo de San Cristóbal (Laguardia, Álava) (Fernández Eraso, 2002b: 45), también usado como establo, o en el poblado de La Renke (Santurde, Álava) (Ortiz et al., 1984: 52). Aunque tradicionalmente se ha establecido una dicotomía en cuanto a la funcionalidad de los yacimientos -asentamientos de habitación relacionados con las actividades cotidianas y funerarios relacionados con las prácticas rituales-, numerosos ejemplos etnográficos demuestran que los rituales están continuamente presentes en las tareas cotidianas (Guerra, 2006: 72). De esta manera, no tendríamos por qué considerar descabellado que este tipo de cerámica con un alto componente simbólico aparezca en yacimientos con diferente función.

Respecto a los aspectos formales de este tipo de recipientes, dentro de la estandarización de esta cerámica (Ontañón, 2005: 231), los expuestos aquí no son una excepción. Todos tienen una cocción controlada con las paredes anaranjadas o rojizas y el interior de la pasta negra, con inclusiones muy pequeñas y en algunos casos inapreciables de visu. En los casos mejor conservados se pueden ver signos de bruñido, posiblemente presentes en todos los ejemplares.

La mayoría de los vasos meseteños tienen entre 110-146 $\mathrm{mm}$ de diámetro de boca, 95$150 \mathrm{~mm}$ de altura y 450-1250 cc de capacidad (Garrido-Pena, 2000: 156). En los estudiados, el diámetro de boca en Trikuaizti I es $100 \mathrm{~mm}$, por debajo de esa media, Pagobakoitza y Tres Montes están dentro de la 
horquilla, con 134 y $120 \mathrm{~mm}$ respectivamente y Gorostiaran Este por encima, con $154 \mathrm{~mm}$. En altura y capacidad, el vaso de Trikuaizti I entra en la horquilla meseteña con $144 \mathrm{~mm}$ de altura y 827 cc, Pagobakoitza y Tres Montes se hallan por encima de la media con 184 y $185 \mathrm{~mm}$ de altura y algo más de $1500 \mathrm{cc}$ de capacidad. Cabe reseñar que aunque estos recipientes están por encima de la media, se han documentado ejemplares mucho más voluminosos, como el vaso - estilo CZM- del yacimiento de Forno dos Mouros (Toques, A Coruña) con una altura aproximada de 190 o $200 \mathrm{~mm}$ y una capacidad estimada de 6000 cc (Prieto et al., 2008: 34).

Con lo expuesto anteriormente, creemos que es incuestionable que los dos fragmentos recuperados en el abrigo de Los Husos I pertenecen a un vaso campaniforme de estilo Internacional. En cuanto a la variante a la que pertenece, podemos asegurar que se trata del estilo ILV. Esta afirmación se apoya en su comparación con los vasos localizados en los yacimientos más cercanos. Se ha comprobado que la anchura de los frisos decorados con puntillados oblicuos, así como aquellos lisos, es aproximadamente la misma, ya sean de la variante MHV, CZM o de la ILV, aunque en esta última en los frisos lisos presenten una o varias líneas horizontales puntilladas (Fig. 10).

En cuanto al uso de cuerdas en la variante CZM, todos los ejemplares de este estudio tienen improntas

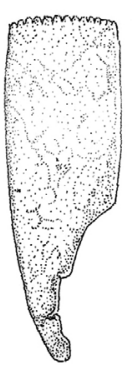

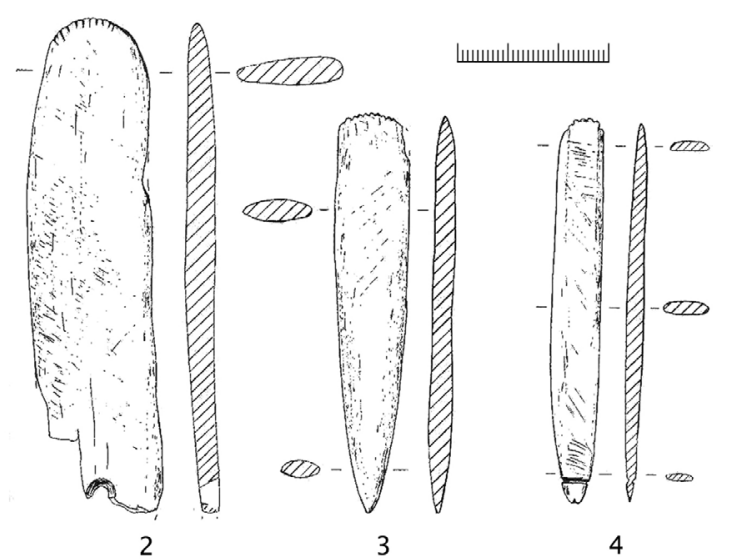
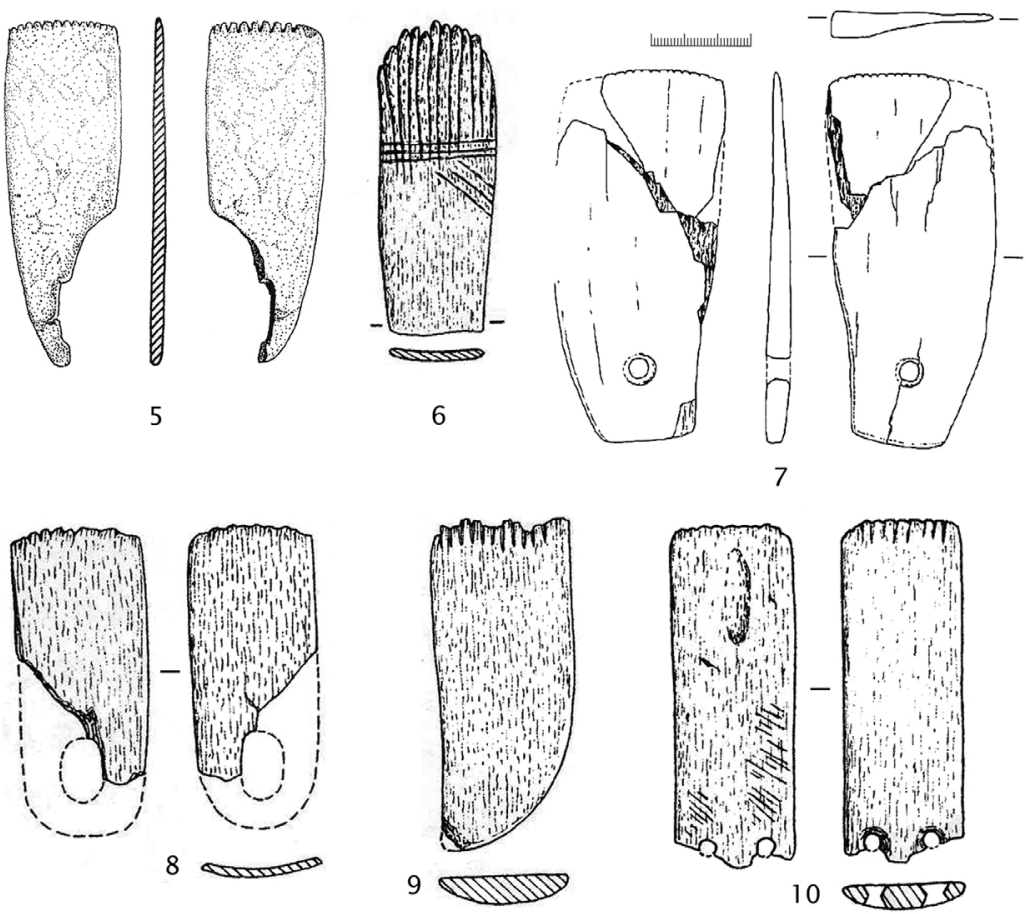

Fig. 11. Gradinas o peines de alfarero peninsulares: 1) Barcella (Torremanzanas, Alicante) (según Borrego et al., 1992); 2-4) Or (Beniarrés, Alicante) (según Pascual, 1998); 5) Zambujal (Condeixa-a-Nova) (según Sangmeister y Schubart, 1969); 6) Senhora da Luz (Rio Maior) (según Leitão et al., 1973); 7) La Draga (Banyoles, Girona) (según Tarrús et al., 1994); 8) Pai Mogo (Lourinhá) (según Spindler y Gallay, 1973a); 9) Furninha (Peniche) (según Delgado, 1884); 10) Abrigo de Carrasca (Torres Vedras) (según Spindler y Gallay, 1973b).

de cuerda con sentido de la torsión en ' $z$ ', a excepción de Larrarte, donde se combinan cuerdas con torsión en 's' y en ' $z$ '. Se ha propuesto que el sentido 
de la torsión de las cuerdas en las decoraciones diferencia las calcolíticas -en ' $\mathrm{z}$ '- de las del Bronce Antiguo -en 's'-. Esta tendencia se cumple en las cerámicas decoradas a cuerda en el País Vasco $(\mathrm{Mu}-$ jika et al., 2009: 115).

\subsection{Peine vs. concha. Técnicas decorativas en el Campaniforme Maritimo}

Partiendo del despiece de los patrones decorativos, hemos observado que el sentido del gesto al realizar las líneas puntilladas oblicuas varía en función de la orientación de su caída. Si esta es hacia la derecha el gesto va de arriba abajo y cuando es hacia la izquierda de abajo arriba (Fig. 12, n. ${ }^{\circ}$ 1). Además, para las impresiones oblicuas no se usa toda la superficie dentada del peine en todas las secuencias, la serie no siempre comienza o termina con la misma impronta.

Observando detenidamente las series de impresiones de las piezas descritas, se aprecian algunas diferencias formales en relación a las improntas, en su anchura, longitud, número de puntos y el espacio entre ellos. La cuestión obligada que se plantea a continuación es la identificación de la herramienta usada para la elaboración de este tipo de decoraciones. En la bibliografía se recogen dos útiles diferentes en la impresión de las líneas de puntos, por un lado, el peine de alfarero y, por otro, el uso de diferentes especies de conchas.

Los peines de alfarero o gradinas son láminas de hueso de contorno elipsoidal o rectangular alargado en cuyo estrecho extremo distal presentan estrías, pequeñas muescas o incipientes dientes (Castro, 1988: 248). Su uso se identifica durante el Neolítico con decoraciones impresas sobre pastas cerámicas, acompañando y probablemente imitando a la cardial. En el Calcolítico se relacionan con la cerámica campaniforme (Rodanés, 1987: 123).

Se encuentran ampliamente documentados en el sur peninsular y Portugal, pero son muy escasos -o inexistentes- en nuestro entorno. En el Levante peninsular se recuperaron tres gradinas neolíticas en cova de l'Or (Beniarrés, Alicante), una de ellas perforada, realizadas sobre diáfisis óseas (Martí,
1977; Vento, 1985; Pascual, 1998: 85); así como otra calcolítica en La Cova de la Barcella (Torremanzanas, Alicante) (Borrego et al., 1992). Por otro lado, en el yacimiento de La Draga (Banyoles, Girona) también se encontró otro ejemplar neolítico (Tarrus et al., 1994: 453). En el s de Portugal, se localizan gradinas en contextos del Neolítico Final y Calcolítico como el Abrigo de Carrasca, Furninha, Pai Mogo, Senhora da Luz o el poblado calcolítico de Zambujal (Spindler, 1981; Sangmeister y Schubart, 1969) (Fig. 10).

Con estas gradinas se consigue hacer las líneas de impresiones cuadrangulares para formar las bandas de la cerámica campaniforme puntillada. Ya en 1957 Jodin se percata de que a diferencia de los que afirman que se decoran punto por punto con punzones, en sus cerámicas hay series de puntos de entre 8 y 10 impresiones, fácilmente replicables con un peine. Con el fin de demostrarlo, realizó una experimentación con un peine de hueso para reproducir los motivos decorativos de las cerámicas campaniformes de Dar Es-Soltan, Marruecos, logrando un resultado muy similar al original (Jodin, 1957).

Por otro lado, Salanova (1992) reflexiona sobre el uso de conchas para realizar esta decoración en la cerámica campaniforme francesa. Identifica los bordes dentados de Cerastoderma -con una impronta de 20-30 mm y 15-20 dientes de entre 1 y 1,5 mm-, Donax vitatus -impronta ligeramente más curva de $15-20 \mathrm{~mm}$ y $17-20$ dientes de $0,5 \mathrm{~mm}-\mathrm{y}$ una no identificada a la que llama Coquille fine-impronta ligeramente curva de 15-20 mm y 16-20 dientes de $1 \mathrm{~mm}$, muy cerca unos de otros- (Salanova, 2000: 41). El uso de conchas se ha identificado en otras regiones como Portugal, Gran Bretaña, Italia o Galicia, donde, tras analizar más de 300 recipientes, se identifican hasta 6 especies de conchas distintas usadas en la decoración de cerámicas campaniformes (Salanova y Prieto, 2011).

Partiendo de estas dos opciones, se han realizado diferentes pruebas experimentales, para después compararlas con las cerámicas arqueológicas en tres aspectos: la forma general de la decoración; la morfología de las impresiones; la longitud y el número de puntos. 
La primera herramienta usada ha sido un peine experimental realizado en una escápula de Ovis aries. Las púas se han ejecutado mediante incisiones, usando una lasca de sílex y sus medidas son las mismas que las de la decoración de los fragmentos de los Husos I -22 mm de longitud y 15 puntos- (Fig. 12, n. 3 ). Con el peine se consiguen unas impresiones cuadradas, líneas rectas y perfectamente alineadas.

Seguidamente, se ha realizado una experimentación similar con cuatro especies de conchas, escogiendo Cerastoderma edule y Donax vittatus porque su uso está documentado en recipientes franceses (Salanova, 2000) y Chlamys varia porque se ha identificado en Galicia junto con las dos anteriores (Prieto et al., 2008; Salanova y Prieto, 2011). También se ha usado Laevicardium oblongum tras observar que con su impronta se pueden obtener impresiones cuadrangulares separadas entre sí (Manen y Salanova, 2010) (Fig. 12, n.o 4).

El objetivo era lograr una impresión lo más similar posible a las decoraciones observadas en las cerámicas arqueológicas. Según el gesto y la posición se pueden lograr secuencias de dientes individualizados o líneas zigzagueantes. Usando la concha en posición vertical con respecto a la pasta, la impronta es una línea zigzagueante -Cerastoderma, Laevicardium y Chlamys - o recta -Donax-. Para lograr un puntillado es necesario inclinar bastante la concha apoyando la cara ventral -Cerastoderma, Laevicardium y Donax- o la dorsal -Chlamys- y hacer muy poca presión, en caso contrario las improntas no son rectángulos individuales, sino que una fina línea las une. En cuanto a la forma de las líneas, las improntas logradas con los ejemplares usados son
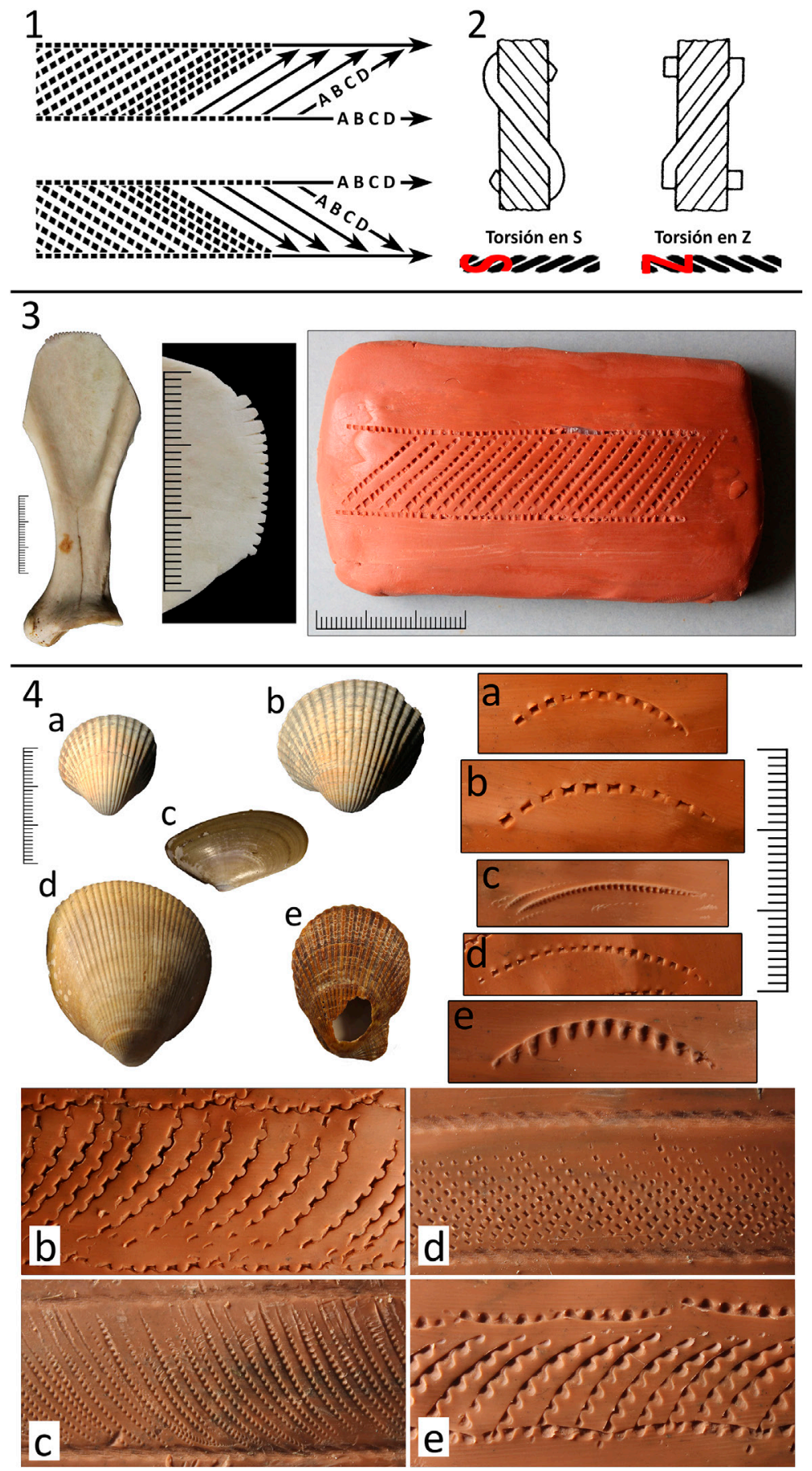

FIG. 12. Decoración cerámica: 1) sentido de las secuencias puntilladas; 2) sentido de la torsión de la cuerda (según Hurley, 1979); 3) peine en escápula de Ovis aries, detalle de los dientes e impronta experimental a peine; 4) conchas e improntas experimentales de Cerastoderma edule ( $a y b$ ), de Donax vittatus (c), de Laevicardium oblongum (d) $y$ de Chlamys varia (e). 
ligeramente arqueadas, este hecho no es un inconveniente para realizar las líneas del interior de los frisos, pero se convierte en un problema para ejecutar las líneas horizontales delimitadoras de los mismos para las variantes MHV e ILV -aunque los dos vasos CZM estudiados también tienen una línea horizontal puntillada-. Sin embargo, usando una superficie pequeña del borde de la concha se evita la curvatura, pero las secuencias logradas son cortas.

En cuanto a las impresiones de las cerámicas arqueológicas, se distinguen dos tipos según su morfología: cuadradas o rectangulares. En las primeras hay una gran variabilidad tanto en el tamaño, entre 0,4 x 0,4 y 1 × $1 \mathrm{~mm}$, como en la separación entre los puntos que pasa de $0,5 \mathrm{~mm}$ en Los Husos I a apenas 0,1 mm en Pagobakoitza. Respecto a los puntos de forma rectangular, la altura de las impresiones es de 0,5-0,6 mm, mientras que la anchura varía desde los $0,8 \mathrm{~mm}$ del fragmento de borde de El Castillo a los 1,2-1,5 mm de La Mina (Fig. 13). En la prueba experimental, con el peine, se logran unas impresiones cuadradas, pero hay que tener en cuenta que es una herramienta fabricada ex profeso, por lo que se puede decidir su longitud y número de púas. Se ha fabricado con la intención de que su impronta se asemeje a la decoración hallada en Los Husos I, por lo que la morfología de sus dientes también se pudiera haber fabricado para que tuvieran forma rectangular. Sin embargo, las conchas de cada especie no están modificadas y son un elemento natural cuya morfología es muy similar y únicamente se diferencian por el tamaño. En las pruebas experimentales hemos obtenido unas improntas de entre $0,5 \mathrm{y}$ $1,6 \mathrm{~mm}$ de anchura y entre 0,6 y $1,7 \mathrm{~mm}$ de altura, por lo que son unas impresiones rectangulares con una separación de entre ellas de entre 0,35 y 1,4 mm que equivalen a entre un 70 y el $100 \%$ de la anchura total del punto.

En las cerámicas la separación entre impresiones oscila entre 0,1 y $0,5 \mathrm{~mm}$ en una horquilla entre el 15 y el $50 \%$ de la anchura de los puntos, con una media del 31,5\%. Por lo tanto, la mayor de las separaciones entre puntos en las cerámicas está lejos de la menor en la experimentación con conchas.

Respecto a la línea de puntos y tras el despiece de las improntas de los fragmentos de Los Husos I, se puede ver que la longitud de la serie era de 22 mm y 15 impresiones. En Etxauri, aunque la longitud de la serie completa es la misma, tiene un mayor número de puntos ligeramente más pequeños y más juntos entre sí, por lo que debió realizarse con un peine de púas más finas (Fig. 13). En La Atalayuela,

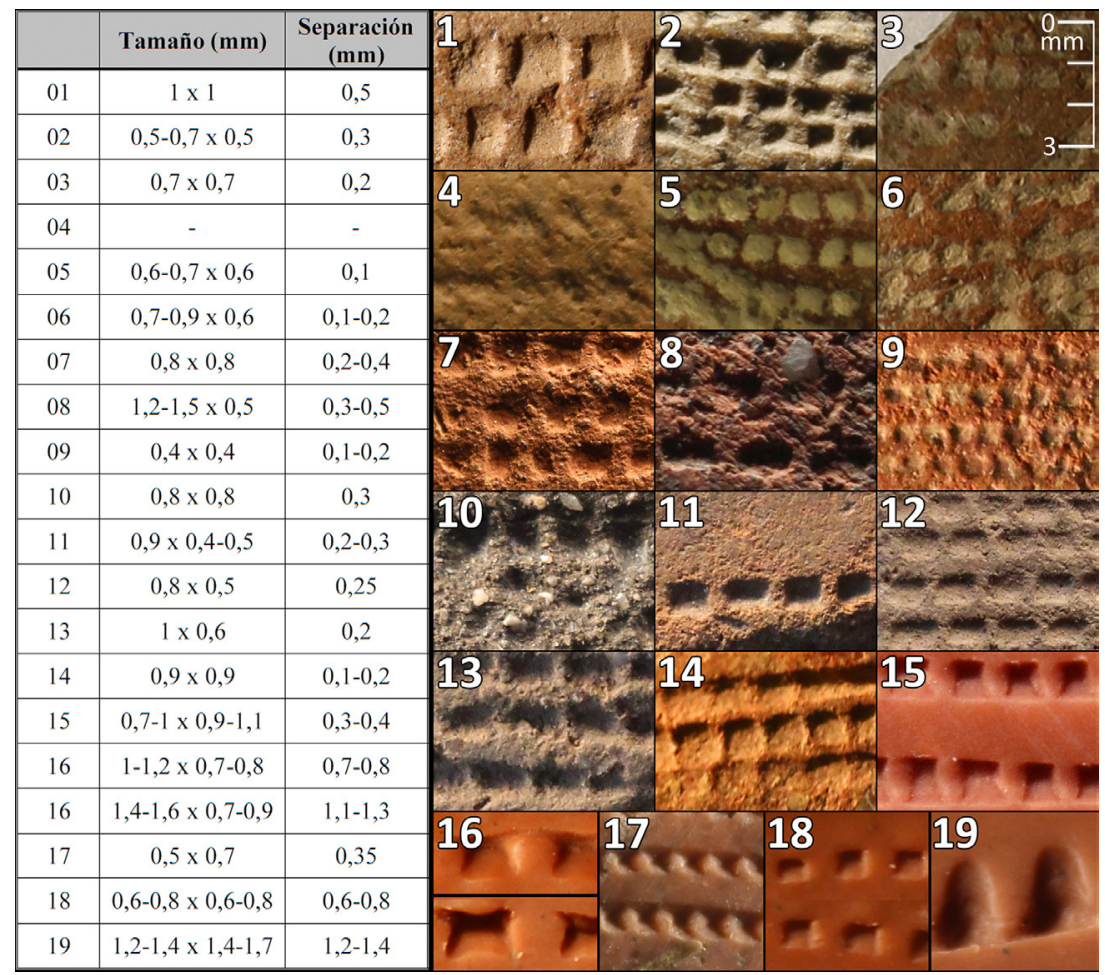

FIG. 13. Detalle y medidas de las improntas puntilladas. 1) Los Husos I; 2) Trikuaizti; 3) Larrarte; 4) Gorostiaran Este; 5-6) Pagobakoitza; 7) Etxauri; 8) La Mina; 9) La Atalayuela; 10) Túmulo IL.C1; 11-13) El Castillo; 14) Tres Montes; 15-18) improntas experimentales con peine (15) y conchas de Cerastoderma edule-ejemplar pequeño y grande-(16), de Donax vittatus (17), de Laevicardium oblongum (18) y de Chlamys varia (19). 
aunque no se ha conseguido realizar el despiece de la decoración, la secuencia presenta impresiones muy pequeñas y juntas, que con 15 puntos por $\mathrm{cm}$ está muy por encima de todos los demás.

Entre las tumbas del valle de Ambrona (Soria) se hace mención a la impronta de un peine en un ejemplar del túmulo de la Peña de la Abuela. En uno de los fragmentos mayores del vaso, pertenecientes al fondo plano, resulta claramente apreciable la huella del peine utilizado para realizar su decoración, completa e individualizada respecto a la línea delimitadora del último friso de puntillado oblicuo. Se trataría de un pequeño peine de $26 \mathrm{~mm}$ de longitud y unos 22 dientes (Rojo et al., 2005: 46).

Las gradinas (Fig. 13) se agrupan en una horquilla entre 3,7 y 7,5 dientes/cm. Entre los peines prehistóricos en hueso, no solo los de alfarero, Provenzano (1991: 8) expone que tienen entre 4 y 7 dientes/cm. Castro (1988: 248) presenta un rango más amplio para los peines de Los Millares y Cueva Alta, de entre 3 y 10 dientes $/ \mathrm{cm}$.

Con todo lo expuesto hasta el momento, y viendo las similitudes de las improntas, creemos acreditado el uso del peine en la decoración tanto de las campaniformes de Los Husos i, como del resto de

\begin{tabular}{|l|c|c|c|}
\hline \multicolumn{1}{|c|}{ Vasos } & $\begin{array}{c}\text { Anchura de } \\
\text { la serie } \mathbf{( m m )}\end{array}$ & $\begin{array}{c}\text { N. }{ }^{\circ} \text { de } \\
\text { impresiones }\end{array}$ & $\begin{array}{c}\text { Impresiones } \\
\text { /cm }\end{array}$ \\
\hline Los Husos I & 22 & 15 & 6,8 \\
\hline Trikuaizti I & 24 & 23 & 9,6 \\
\hline Pagobakoitza & 11 & 12 & 10,1 \\
\hline Etxauri & 22 & 19 & 8,6 \\
\hline El Castillo & 15 & 13 & 8,6 \\
\hline El Castillo & 12 & 9 & 7,5 \\
\hline Tres Montes & 24 & 22 & 9,1 \\
\hline Peńa de la Abuela & 26 & 22 & 8,4 \\
\hline \multicolumn{1}{|c|}{ Peines } & Anchura de la & N. ${ }^{\circ}$ de dientes & Dientes \\
o gradinas & serie (mm) \\
\hline Or (2039) & 21 & 11 & 5.2 \\
\hline Or (2040) & 15 & 9 & 6 \\
\hline Or (2002) & 8 & 6 & 7,5 \\
\hline Barcella & 39 & 20 conserv. & 5,9 \\
\hline La Draga & 38 conserv. & 14 conserv. & 3,7 \\
\hline
\end{tabular}

FIG. 14. Campaniformes maritimos y peines de alfarero conservados: anchura de la secuencia y número de impresiones o dientes. los yacimientos estudiados. La forma más alargada de los puntos de La Mina, El Castillo y el fragmento de Pagobakoitza induce a pensar que las decoraciones de estos yacimientos pudieran haber sido realizadas mediante conchas, aunque este no es un factor determinante ya que con un peine también se puede realizar esta forma. Además, uno de los fragmentos de El Castillo presenta una línea de puntillado con el característico arqueamiento que se produce en las improntas de concha. Aun así, creemos que la separación que existe entre las improntas de puntos de las cerámicas arqueológicas las hace incompatibles con el uso de conchas. Por lo tanto, las decoraciones de todas las cerámicas analizadas estarían realizadas mediante el uso de un peine.

\section{Conclusiones}

Hemos revisado un total de 14 vasos repartidos en 11 yacimientos, todos de origen funerario a excepción de Etxauri (Navarra) y Los Husos I (Laguardia, Álava). En el caso de este último, a pesar de haber recuperado los dos fragmentos en dos excavaciones distintas con estratigrafías complicadas de equiparar y dentro de niveles con mucho material cerámico y muy fragmentado, se ha podido demostrar que pertenecen al mismo recipiente, un vaso campaniforme estilo Internacional, variante ILV. Es importante destacar la presencia en esta provincia de este tipo de cerámica, más en concreto en la comarca de la Rioja Alavesa, ya que se ha considerado que la ausencia de esta no se debe a deficiencias en la investigación, sino a una supuesta 'marginación' del territorio en la primera fase de irrupción del Campaniforme, la correspondiente a los estilos llamados Internacionales (Alday, 2001: 141).

Pese al pequeño tamaño de la mayoría de los fragmentos estudiados, se puede discernir a qué variante pertenece cada vaso y en cuanto a sus características todos se asemejan en la ejecución, son de paredes finas, con desgrasantes de pequeño tamaño y si están bien 
conservados se observa el bruñido de las paredes. Tras el trabajo de experimentación y comparación creemos demostrado que las decoraciones estudiadas se han realizado mediante un peine o gradina cuyo borde dentado tenía una longitud de entre 11 y $24 \mathrm{~mm}$ y con un número de púas que varía de 9 a 23. La morfología de las impresiones, la rectitud de las secuencias y, sobre todo, la separación entre los puntos las hace incompatibles con el uso de conchas.

Hemos comprobado que el sentido de las líneas puntilladas oblicuas cambia en función de la orientación de su caída, que no siempre se usa todo el borde dentado del peine y que al menos en Larrarte se usaron dos cuerdas distintas - por el sentido de la torsión- en la decoración CzM. Todos estos detalles nos acercan a los gestos que la alfarera llevó a cabo para confeccionar este tipo de recipientes tan singulares.

La metodología llevada a cabo en este trabajo para estos 14 ejemplares puede aplicarse para todas las decoraciones puntilladas -Lineal, Marítimo, Geométrico- dentro del fenómeno campaniforme y puede ser una herramienta útil para identificar la mano de una misma alfarera en más de un recipiente.

\section{Bibliografía}

Alday, A. (2001): "Vías de intercambio y promoción del Campaniforme marítimo y mixto sobre el interior peninsular", Cuadernos de Arqueología de la Univ. de Navarra, 9, pp. 111-174.

Andrés, M. T. y Barandiarán, I. (2004): "La tumba calcolítica de La Atalayuela, treinta y cinco años después", Salduie, 4, pp. 85-124.

Andrés, M. T.; García, M. L. y Sesma, J. (1996): "El sepulcro calcolítico de Tres Montes (Las Bardenas Reales, Navarra)". En Bueno, P. y Balbín, R. de (coords.): II Congreso de Arqueología Peninsular ( $\mathrm{Za}$ mora, 1996). Vol. 2. Neolítico, Calcolítico y Bronce. Zamora, pp. 11-22.

Andrés, M. T.; García, M. L. y Sesma, J. (2000): “El sepulcro calcolítico de Tres Montes (Las Bardenas Reales, Navarra). Intervención de urgencia 1991 y campañas de 1996 y 1997", Trabajos de Arqueología Navarra, 15, pp. 315-321.
Andrés, M. T.; García, M. L. y Sesma, J. (2007): "Tres Montes. Un sepulcro singular del III milenio en las Bardenas Reales". En La tierra te sea leve: Arqueología de la muerte en Navarra. Pamplona: Gob. de Navarra, pp. 84-88.

Apellániz, J. M. (1973): Corpus de materiales de las culturas prehistóricas con cerámica de la población de cavernas del País Vasco meridional. Munibe, Suplemento 1. Donostia.

Apellániz, J. M. (1974): "El grupo de Los Husos durante la Prehistoria con cerámica en el País Vasco", Estudios de Arqueología Alavesa, 7, pp. 7-409.

Aranzadi, T.; Barandiarán, J. M. y Eguren, E. (1919): "Exploración de seis dólmenes de la sierra de Aizkorri II. Los dólmenes", Euskalerriaren Alde, x, 186, pp. 245-262.

Barandiarán, I. (1978): "La Atalayuela: fosa de inhumación colectiva del Eneolítico en el Ebro Medio", Principe de Viana, 152-153, pp. 381-422.

Barandiarán, J. M. y Fernández Medrano, D. (1971): "Excavación del dolmen de San Martín". En Investigaciones Arqueológicas en Álava, 1957-1968. Vitoria, pp. 147-173.

Barandiarán, I. y Vallespí, E. (1980): Prehistoria de Navarra. Trabajos de Arqueología de Navarra, 2. Pamplona: Diput. Foral de Navarra.

Blanco, A. (2015): "Emulación decorativa y cerámicas ancestrales. Posibles fuentes de inspiración de las alfareras meseteñas de la Edad del Bronce", Zephyrus, LXXVI, pp. 39-56. https://dx.doi.org/10.14201/ zephyrus2015763956.

Bonilla, A.; Vila, M. C. y Fábregas, R. (2006): "Nuevas perspectivas sobre el espacio doméstico en la Prehistoria Reciente del no: el Poblado de Os Remedios (Moaña, Pontevedra)", Zephyrus, lix, pp. 257-273.

Borrego, M.; Sala, F. y Trelis, J. (1992): La "Cova de la Barcella" (Torremanzanas, Alicante). Catálogo de fondos del museo arqueológico, iv. Alicante: MARQ.

Bronk Ramsey, C. y Lee, S. (2013): "Recent and Planned Developments of the Program Oxcal”, Radiocarbon, 55 (2-3), pp. 720-730.

Calvo Trías, M. y García Roselló, J. (2014): “Acción técnica, interacción social y práctica cotidiana: propuesta interpretativa de la tecnología”, Trabajos de Prehistoria, 71 (1), pp. 7-22.

Cardoso, J. L. (2011): "O povoado calcolítico da Penha Verde (Sintra)”, Estudos Arqueológicos de Oeiras, 18, pp. 467-551.

Cardoso, J. L.; Cardoso, G. y Encarnação, J. D. (2013): "O campaniforme de Freiria (Cascais)", Estudos Arqueológicos de Oeiras, 20, pp. 525-588. 
Carmona, E. (2013a): "Antiguas noticias, nuevas interpretaciones: la ocupación campaniforme del Cerro del Castillo de Burgos", Saguntum, 45, pp. 49-64. https://doi.org/10.7203/SAGVNTVM.45.2055.

Carmona, E. (2013b): El Calcolitico en la Cuenca Media del Arlanzón (Burgos, España). Comunidades campesinas, procesos históricos y transformaciones. BAR Intern. Ser., 2559. Oxford: Archaeopress.

Castro, Z. (1988): "Peines prehistóricos peninsulares", Trabajos de Prehistoria, 48, pp. 243-258.

Delgado, J. F. N. (1884): "La grotte de Furninha a Peniche". En Congrès Intern. d'Anthropologie et d'Archéologie Préhistoriques. Compte-Rendu Neuvième Session à Lisbonne, 1880. Lisboa: Typographie de l'Académie Royale des Sciences, pp. 207-278.

Fernández Eraso, J. (2000): "Excavaciones en la Sierra de Cantabria (Los Husos I. Elvillar)", Arkeoikus$k a, 99$, pp. 44-48.

Fernández Eraso, J. (2001): "Excavaciones en la Sierra de Cantabria (Los Husos i. Elvillar)", Arkeoikuska, 00, pp. 39-45

Fernández Eraso, J. (2002a): "El abrigo de Los Husos I (Elvillar)", Arkeoikuska, 01, pp. 68-72.

Fernández Eraso, J. (2002b): "Nuevos datos de la Prehistoria reciente en la Rioja Alavesa: Neolítico-Bronce". En García Fernández, E. (coord.): Espacio, sociedad y economia: Actas de las Primeras Jornadas de Estudios Históricos de la Rioja Alavesa. Vitoria-Gasteiz: Diput. Foral de Álava, pp. 37-56.

Fernández Eraso, J. y Polo, A. (2008-2009): "Establos en abrigos bajo roca de la Prehistoria Reciente: su formación, caracterización y proceso de estudio. Los casos de Los Husos y de San Cristóbal”, Krei, 10, pp. 39-51.

García Rivero, D.; Jurado, J. M. y Taylor, R. (2016): "Bell Beaker and the evolution of resource management strategies in the southwest of the Iberian Peninsula", Journal of Archaeological Science, 72, pp. 10-24.

Garrido-Pena, R. (2000): El Campaniforme en la Meseta Central de la Peninsula Ibérica (c. 2500-2000 $A C)$. BAR Intern. Ser., 892. Oxford: Archaeopress.

Guerra, E. (2006): "Sobre la función y el significado de la cerámica campaniforme a la luz de los análisis de contenidos", Trabajos de Prehistoria, 63 (1), pp. 69-84.

Harrison, R. J. (1977): The Bell Beaker Cultures of Spain and Portugal. American School of Prehistoric Research Bulletin, 35. Cambridge-Massachusetts.

Hurley, W. M. (1979): Prehistoric cordage. Identification of impressions on pottery. Washington: Taraxacum.
Hurtado, V. y Amores, F. (1982): "Relaciones culturales entre el sudeste francés y La Pijotilla (Badajoz) en el Calcolítico: las pastillas repujadas y el Campaniforme cordado", Habis, 13, pp. 189-209.

Jodin, A. (1957): "La céramique campaniforme de Dar Es-Soltan", Bulletin de la Société Préhistorique Française, 54, pp. 44-48.

Leitão, M.; North, T. y Da Veiga, O. (1973): "O povoado pré-histórico da Serra da Espargueira (Belas)". En Actas II Jornadas Arqueológicas (Lisboa, 1972). Lisboa, vol. 1, pp. 143-157.

LóPEZ DE OCÁRIZ, J. (2014): "La cerámica campaniforme en la Rioja Alavesa a la luz de los últimos descubrimientos", $C K Q, 4$, pp. 27-44.

López de Ocáriz, J.; Camarero, C.; Arévalo, E.; Abaunza, A.; Agirre, A.; Domínguez, E.; García Rojas, M.; Pérez Fernández, A. J. y Sánchez, A. (2016): "Abrigo de Los Husos I (Laguardia, Álava)", Arkeoikuska, 14, pp. 92-94.

Manen, C. y Salanova, L. (2010): "Les impressions de coquilles marines à front denté dans les décors céramiques néolithiques". En Manen, C.; Convertini, F.; Binder, D. y Sénépart, I. (dirs.): Séance de la Société Préhistorique Française. Premières sociétés paysannes de Méditerranée occidentale. Structures des productions céramiques (Toulouse, 2007). Mémoires de la Société Préhistorique Française, 5. Nanterre, pp. 57-64.

Marqués de Loriana (1943): "Dos nuevos hallazgos megalíticos en la provincia de Álava", Archivo Español de Arqueología, XVI, pp. 206-208.

MarquÉs de Loriana (1953): "Salcedo (Álava). Molinilla", Archivo Español de Arqueología, I, pp. 191.

Martí, B. (1977): Cova de l'Or (Beniarrés, Alicante). Serie de Trabajos Varios, 51. Valencia: SIP.

Mujika, J. A. (1986): “Túmulos de Trikuaizti, Beasain (Guipúzcoa)”, Arkeoikuska, 85, pp. 38-40.

Mujika, J. A. y Armendáriz, A. (1991): "Excavaciones en la estación megalítica de Murumendi (Beasain, Guipúzcoa)", Munibe (Antropologia-Arkeologia), 43, pp. 105-165.

Mujika, J. A.; Peñalver, X.; Tarriño, A. y Telleria, E. (2009): "Haltzerreka (Guipúzcoa): Un asentamiento del Bronce Antiguo al aire libre en un medio de montaña”, Kobie (Serie Paleoantropologia), 28, pp. 89-120.

Narvarte, N. (2005): Gestión funeraria dolménica en la cuenca Alta y Media del Ebro: fases de ocupación y clausuras. Logrońo: Instit. Estudios Riojanos,

Narvarte, N. (2007): "Revisión del dolmen de La Mina (Molinilla, Álava). Aspectos arquitectónicos 
y nuevos datos materiales", Caesaraugusta, 78, pp. 145-158.

Ontañón, O. (2005): "El Campaniforme en la Región Cantábrica”. En Rojo, M.; Garrido, R. y GarCía Martínez de Lagrán, I. (coords.): El Campaniforme en la Peninsula Ibérica. Salamanca: JcyL, pp. 227-244

Ortiz, L.; Lobo, P. J. y Vivanco, J. J. (1984): “Informe preliminar de la $1 .^{a}$ campańa de excavaciones en el poblado eneolítico de La Renke (Santurde, Álava)", Munibe (Antropologia-Arkeologia), 36, pp. 51-54.

Pascual, J. L. (1998): Utillaje óseo, adornos e idolos neolíticos valencianos. Serie de Trabajos Varios, 95. Valencia: sip.

Polo, A. y Fernández Eraso, J. (2010): "Same anthropogenic activity, different taphonomic processes: a comparison of deposits from Los Husos I \& II (Upper Ebro Basin, Spain)", Quaternary International, 214 (1-2), pp. 82-97. https://doi.org/10.1016/j. quaint.2009.10.022.

Prieto, M. P. (2001): La cultura material cerámica en la Prehistoria Reciente de Galicia: Yacimientos al aire libre. TAPA-Traballos en Arqueoloxía da Paisaxe, 20. Santiago de Compostela.

Prieto, M. P.; Lantes, Ó. y Martínez Cortizas, A. (2008): "O Campaniforme cordado de Forno dos Mouros (Toques, A Coruña)", Cuadernos de Estudios Gallegos, 121, pp. 31-51.

Provenzano, N. (1991): “12. Fiches des Peignes". En Camp Fabrer, H. (ed.): Fiches typologiques de l'industrie osseuse préhistorique. Cahier IV. Objets de parure. Aix en Provence: Univ. de Provence, pp. 1-14.

Reimer, P. J.; Bard, E.; Bayliss, A.; Beck, W.; Blackwell, P.; Bronk, C.; Buck, C.; Cheng, H.; EdWards, L.; Friedrich, M.; Grootes, P.; Guilderson, T.; Haflidason, H.; Hajdas, I.; Hatté, Ch.; Heaton, T.; Hoffmann, D.; Hogg, A.; Hughen, K.; Kaiser, F.; Kromer, B.; Manning, S.; Niu, M.; Reimer, R.; Richards, D.; Scott, M.; Southon, J.; Staff, R.; Turney, Ch. y Van der Plicht, J. (2013): "IntCal13 and Marine13 radiocarbon age calibration curves 0-50,000 years cal вр", Radiocarbon, 55 (4), pp. 1869-1887.

RoDANÉs, J. M. (1987): La industria ósea prehistórica en el Valle del Ebro. Zaragoza: Diput. General de Aragón.

RodANÉs, J. M. (1992): "El vaso campaniforme marítimo de Mallén (Zaragoza) y su relación con los estilos antiguos del Valle del Ebro". En Utrilla, M. P. (coord.): Homenaje a J. Maluquer de Motes. Ponencias y Comunicaciones. Zaragoza, pp. 599-617.
Rojo, M.; Kunst, M.; Garrido, R.; García MartíNEZ de LAGrÁN, I. y Morán, G. (2005): Un desafio a la eternidad: Tumbas monumentales del Valle de Ambrona. Memorias Arqueología en Castilla y León, 14. Soria.

Salanova, L. (1992): "Le décor à la coquille dans le campaniforme du Sud-Finistère", Revue Archéologique de l'Ouest, 9, pp. 79-81.

Salanova, L. (2000): La question du Campaniforme en France et dans les Îles Anglo Normandes. Productions, chronologie et rôles d'un standard céramique. Paris: Édit. Comité des Travaux Historiques et Scientifiques Société Préhistorique Française.

Salanova L. (2001): "Technological, ideological or economic European union? The variability of Bell Beaker decoration". En Nicolis, F. (ed.): Bell Beakers Today. Pottery, People, Culture, Symbols in Prehistoric Europe. Proceedings Intern. Colloquium Riva del Garda (Trento, 1998). Trento: Ufficio Beni Archeologici, vol. I, pp. 91-102.

Salanova, L. y Prieto, M. P. (2011): "Capítulo 32. Una aproximación al empleo de la concha para decorar la cerámica campaniforme en Galicia”. En PRIEto, M. P. y Salanova, L. (coords.): Las comunidades campaniformes en Galicia. Cambios sociales en el III $y$ II milenios $B C$ en el $N W$ de la Peninsula Ibérica. Pontevedra: Diput. de Pontevedra, pp. 297-307.

Sangmeister, E. y Schubart, H. (1969): "Grabungen in der Kupferzeitlichen Befestigung von Zambujal, Portugal", Madrider Mitteilungen, 10, pp. 11-44.

Spindler, K. (1981): Cova da Moura. Madrider Beiträger, 7. Mainz.

Spindler, K. y Gallay, G. (1973a): "Die Tholos von Pai Mogo/Portugal", Madrider Mitteilungen, 13, pp. 38-108.

Spindler, K. y Gallay, G. (1973b): Kupferzeitliche Siedlung und Begräbnisstätten von Matacães in Portugal. Madrider Beiträge 1. Mainz.

Uríbarri, J. L.; Martínez GonzÁlez, J. M. y Leis, I. (1987): Primeros asentamientos humanos en la ciudad de Burgos. Burgos.

Tarrús, J.; Chinchilla, J. y Bosch, A. (1994): "La Draga (Banyoles): Un site lacustre du Néolitique Ancien Cardial. Catalogne”, Bulletin de la Société Préhistorique Française, 91 (6), pp. 449-456.

Vento, E. (1985): "Ensayo de clasificación sistemática de la industria ósea neolítica. La Cova de l'Or (Beniarrés, Alicante)", Saguntum, 19, pp. 31-83. 